\title{
РАЗДЕЛ 2
}

\section{НАУЧНЫЕ СТАТЬИ}

\section{Сравнительная оценка безопасности глубинных захоронений радиоактивных отходов открытого и замкнутого топливного циклов: радиологическая миграционная эквивалентность}

\author{
Иванов В.К..$^{1,2,3}$, Спирин Е.В. ${ }^{3}$, Меняйло А.Н. ${ }^{1,2}$, Чекин С.Ю. ${ }^{1,2}$, Ловачёв С.С..$^{1,2}$, \\ Корело А.М. ${ }^{1,2}$, Туманов К.А. ${ }^{1,2}$, Соломатин В.М. ${ }^{3}$, Лопаткин А.В. ${ }^{3}$, Адамов Е.О. ${ }^{3}$ \\ ${ }^{1}$ МРНЦ им. А.Ф. Цыба - филиал «НМИЦ радиологии» Минздрава России, Обнинск; \\ 2 ООО «НПК «Мединфо», Обнинск; \\ ${ }^{3}$ АО «Прорыв», Москва
}

\begin{abstract}
В работе рассмотрен вопрос достижения радиологической миграционной эквивалентности от глубинного захоронения РАО при двухкомпонентной ядерной энергетике. Получены сравнительные оценки радиологического риска в двух сценариях: тепловые реакторы (ТР) в открытом топливном цикле; тепловые и быстрые реакторы (ТР+БР) в замкнутом топливном цикле. Для учёта миграционной способности радионуклидов при оценке потенциального воздействия на окружающую среду использованы коэффиициент распределения (distribution coefficient) и коэффициент задержки (retardation factor). Дана оценка потенциальной годовой эфффективной дозы населения от радионуклидов, вышедших в разное время на поверхность почвы из глубинного захоронения по указанным сценариям ТР и ТР+БР. Получены также оценки лучевых нагрузок населения при потреблении воды из колодца над глубинным захоронением. Приводятся величины пожизненного атрибутивного риска (LAR) онкосмертности по сценариям (TP, TP+БР). Показано, что величина LAR от TP+БР ниже значения LAR от природного урана, т.е. после достижения радиологической эквивалентности (100 лет выдержки) наблюдается на всём интервале времени (до $10^{9}$ лет) выполнение условия радиологической миграционной эквивалентности. Показано также, что величина LAR от TP+БР примерно в 100 раз ниже «пренебрежимо малого» уровня по действующим НРБ-99/2009 $\left(10^{-6}\right)$. Приведённые данные свидетельствуют, что величина LAR для TP в 360 раз больше величины LAR для TP+БР. Для достижения радиологической миграционной эквивалентности для TP требуется более 1 млн лет после захоронения. При потреблении колодезной воды для ТР+БР величина LAR не превышает $10^{-5}$ год $^{-1}$, для TP соответствующее значение LAR составляет $10^{-3}$ год $^{-1}$ (социально неприемлемый уровень). Основными дозо-риск-образующими радионуклидами при потреблении колодезной воды на временном интервале до 10 тыс. лет после захоронения являются ${ }^{241} \mathrm{Am},{ }^{239} \mathrm{Pu} и{ }^{240} \mathrm{Pu}$. Показаны уровни радиологического ущерба при захоронении отходов ядерной энергетики, основанной на ТP.
\end{abstract}

Ключевые слова: радиологическая эквивалентность, радиологическая миграционная эквивалентность, ожидаемые эфрфективные дозы, тепловые реакторы, быстрые реакторы, пожизненный атрибутивный риск, радиологический ущерб.

\section{Введение}

Ранее было показано [1-3], что требуется около 100 лет выдержки отработавшего ядерного топлива реактора на быстрых нейтронах (БР) для достижения его радиологической эквивалентности с соответствующей массой уранового сырья - для выравнивания их потенциальных

Иванов В.К. - зам. директора по научн. работе МРНЦ им. А.Ф. Цыба, гл. радиоэколог ПН «Прорыв», Председатель РНКРЗ, чл.-корр. PАН, д.Т.н.; Меняйло А.Н. - вед. научн. сотр., к.б.н.; Чекин С.Ю.* - зав. лаб.; Ловачёв С.С. - мл. научн. сотр.; Корело А.М. - ст. научн. сотр.; Туманов К.А. - зав. лаб., к.б.н. МРНЦ им. А.Ф. Цыба - филиал ФГБУ «НМИЦ радиологии» Минздрава России, ООО «НПК «Мединфо». Спирин Е.В. - гл. научн. сотр. отдела гл. радиоэколога ПН «Прорыв», д.б.н.; Соломатин В.М. - нач. отдела гл. радиоэколога ПН «Прорыв», к.б.н.; Лопаткин А.В. - научн. рук. по РЭ, д.т.н.; Адамов Е.О. - научн. рук. ПН «Прорыв», д.т.н., проф. АО «Прорыв». *Контакты: 249035, Калужская обл., Обнинск, ул. Королёва, 4. Тел.: (484) 399-30-79; e-mail: nrer@obninsk.com. 
канцерогенных рисков. Актуальным остаётся вопрос о возможности достижения радиологической миграционной эквивалентности (на интервалах времени 10 тыс. лет и более) при глубинном захоронении радиоактивных отходов (РАО) от совместного использования тепловых и быстрых реакторов в рамках двухкомпонентной стратегии дальнейшего развития атомной энергетики. Рассмотрим последовательно решение указанной проблемы.

Радиационная безопасность на объектах использования ядерной энергетики основана на выполнении норм и правил, обеспечивающих допустимый риск воздействия на персонал и население. Мониторинг выбросов и сбросов радионуклидов в окружающую среду при нормальной эксплуатации атомных станций также показывает, что радиационное воздействие на население не превышает допустимых уровней облучения и риска для здоровья [4-7].

Проблемной областью ядерной энергетики является наработка высокоактивных отходов, которые должны быть изолированы от окружающей среды для предотвращения воздействия на современное и будущее поколение людей. С переходом на замкнутый топливный цикл в двухкомпонентной ядерной энергетике с быстрыми реакторами отработавшее топливо и тепловых и быстрых реакторов становится энергетическим сырьём, в отходы не переходят делящиеся материалы, а часть отходов может быть сожжена в быстрых реакторах. Так, радиотоксичность отходов уменьшится в 10 раз, если из отработавшего ядерного топлива выделить и рециклировать Pu, и в 100 раз, если дополнительно будут сжигаться минорные актиниды [8, 9]. Меньшая потенциальная опасность высокоактивных отходов, при том, что быстрые реакторы нарабатывают больше долгоживущих радионуклидов по сравнению с тепловыми реакторами, должна быть одним из доказательств преимущества замкнутого топливного цикла.

Долгоживущие высокоактивные отходы предполагается захоранивать в глубинных геологических захоронениях. Для оценки безопасности отходов в таких захоронениях в долгосрочной перспективе важно знать не только общую активность, но и время, когда отходы можно считать частью геосферы Земли. В качестве эталона сравнения здесь может выступать урановая руда, масса которой была использована для изготовления ядерного топлива. Такой подход осуществлён при развитии принципа радиационной эквивалентности между потенциальной биологической опасностью РАО и использованного природного урана [8]. В соответствии с этим принципом установлены требования к количественным параметрам выделения минорных актиноидов и отдельных продуктов деления [8, 10-12]. Выполнение требований радиационной эквивалентности позволяет сократить время наступления баланса потенциальной биологической опасности до 300 лет и менее после переработки отработавшего ядерного топлива. Это доказывалось неоднократно путём сопоставления радиотоксичности долгоживущих высокоактивных отходов и эквивалентной массы природного урана для изготовления ядерного топлива как отечественными исследованиями [10-12], так и зарубежными [13-15].

Основываясь на том, что такие радионуклиды, как ${ }^{79} \mathrm{Se},{ }^{99} \mathrm{Tc},{ }^{129} \mathrm{I},{ }^{126} \mathrm{Sn}$, обладают большими периодами полураспада, большим вкладом в активность отходов и высокой подвижностью в геологических породах, в документе [16] делается предположение о том, что наибольшую опасность радиологического риска изолированных в глубинном захоронении долгоживущих отходов представляют именно эти радионуклиды. Однако такой вывод может быть некорректным в сценарии с потреблением радионуклидов с питьевой водой из колодцев на загрязнённой вышедшими в окружающую среду радионуклидами из захоронения.

Цель настоящей работы состоит в проведении сравнительной оценки безопасности глубинных захоронений РАО в двух сценариях развития ядерной энергетики - на тепловых реак- 
торах в открытом топливном цикле и в замкнутом цикле с использованием тепловых и быстрых реакторов, а также в сценариях загрязнения почвы и колодезной воды на месте выхода радионуклидов на поверхность почвы. Оценка безопасности захоронений проводится на основе расчёта радиологических рисков для населения, проживающего в непосредственной от них близости. Влияние на безопасность захоронений актиноидов и продуктов деления, накопленных в РАО, определяется вкладом каждого из них в суммарный радиологический риск для населения, в зависимости от путей воздействия и сценариев развития ядерной энергетики.

Для учёта миграционной способности радионуклидов при оценке потенциального воздействия на окружающую среду используют коэфффициент распределения $\boldsymbol{K}_{\boldsymbol{d}}$ (distribution coefficient) между жидкой и твёрдой фазами в приближении равновесного процесса обмена между этими фазами в почве и геологических породах [10, 17-20]. С помощью коэфффициента распределения определяют коэффрициент задержки $\boldsymbol{k}_{r}$ (retardation factor), который интерпретируют как коэффрициент уменьшения скорости проникновения радионуклидов в горной породе по сравнению с конвективной и дифффузионной скоростью движения воды, хотя на самом деле он равен отношению полной активности радионуклидов в некотором объёме почвы или породы к активности, содержащейся в водном растворе внутри этого объёма.

Коэффрициенты распределения и задержки являются одними из самых больших источников неопределённости в расчётах распространения радионуклидов в горной породе в случае разрушения инженерных барьеров глубинного захоронения и растворения содержимого отходов в воде. Эксперименты по их определению не настолько длительные, чтобы наступило равновесие содержания радионуклидов в жидкой и твёрдой фазах, и это приводит к заниженным оценкам коэфффициентов [21]. Кроме того, коэффициенты распределения сильно зависят от фризико-химических свойств среды - от рН, минерального состава породы и др. [17-19, 22]. Материалы с более высоким значением $\boldsymbol{K}_{\boldsymbol{d}}$ могут быть использованы в качестве барьеров от распространения захороненных радионуклидов. Так, глинистые минералы, вводимые при цементировании жидких РАО, снижают скорость выщелачивания цезия более чем в 5 раз [23].

Значения $\boldsymbol{K}_{\boldsymbol{d}}$ имеют существенную неопределённость. Так, в обзоре для департамента энергии США для Am наиболее подходящей величиной для песчаных почв считается 1100 л/кг с размахом от 275 до 1925 л/кг, а для глинистых почв лучшей величиной является 8500 л/кг с размахом от 4250 до 12750 л/кг [23]. Распределение величин $\boldsymbol{K}_{\boldsymbol{d}}$ подчиняется логнормальному закону [17, 24-27]. В документе МАГАТЭ (TECDOC-1616) [17] для песчаных почв диапазон изменения $\boldsymbol{K}_{\boldsymbol{d}}$ для Am от 67 до 37000 л/кг со средним геометрическим значением 1000 л/кг. Для глинистой почвы среднее геометрическое значение $K_{d}$ составляет 4200 л/кг. Аналогичная ситуация со всеми радионуклидами.

В реальной ситуации при выбранном местоположении глубинного захоронения для прогноза распространения радионуклидов и воздействия на окружающую среду может быть осуществлён выбор наиболее подходящих коэффицциентов распределения, учитывающих физикохимические свойства горных пород. Для сравнительных оценок уровней воздействия на окружающую среду при разных составах РАО в глубинном захоронении можно использовать упрощённый подход с сопоставлением радиотоксичности и изменения её во времени, как это было сделано для отходов быстрого и теплового реактора для определения времени наступления радиологической эквивалентности [2]. 


\section{Материалы и методы}

\section{Оценка эффрективных доз облучения}

Радионуклидный состав отходов открытого и замкнутого топливных циклов рассчитан моделированием развития ядерной энергетики до 2100 г. на тепловых реакторах и тепловых вместе с быстрыми реакторами [2]. По оценкам к 2100 г. ресурс природного урана составит 542 тыс. т. Накопленная к 2100 г. активность наиболее значимых по радиотоксичности радионуклидов актиноидов и продуктов деления - в двух вариантах развития ядерной энергетики приведены в табл. 1.

\section{Активность долгоживущих радионуклидов в отходах ядерной энергетики на тепловых реакторах и одновременно с введением в эксплуатацию быстрых реакторов на 2100 г., Бк}

\begin{tabular}{|c|c|c|c|c|c|}
\hline Нуклид & $\begin{array}{l}\text { Тепловые } \\
\text { реакторы }\end{array}$ & $\begin{array}{c}\text { Тепловые и быстрые } \\
\text { реакторы }\end{array}$ & Нуклид & $\begin{array}{l}\text { Тепловые } \\
\text { реакторы }\end{array}$ & $\begin{array}{c}\text { Тепловые и быстрые } \\
\text { реакторы }\end{array}$ \\
\hline${ }^{235} \mathrm{U}$ & 6 6,3E+13 & & ${ }^{229} \mathrm{Th}$ & $\overline{5} 5,96 \mathrm{E}+11$ & $1,62 \mathrm{E}+12$ \\
\hline${ }^{236} \mathrm{U}$ & $9,92 \mathrm{E}+14$ & $1,02 E+12$ & ${ }^{230} \mathrm{Th}$ & $1,55 \mathrm{E}+12$ & $2,21 \mathrm{E}+11$ \\
\hline${ }^{238} \mathrm{U}$ & $9,65 E+14$ & $1,4 \mathrm{E}+12$ & ${ }^{231} \mathrm{~Pa}$ & $1,5 \mathrm{E}+11$ & $8,66 \mathrm{E}+10$ \\
\hline${ }^{238} \mathrm{Pu}$ & $6,51 \mathrm{E}+18$ & $1,77 \mathrm{E}+17$ & ${ }^{79} \mathrm{Se}$ & $9,74 \mathrm{E}+14$ & $6,50 \mathrm{E}+04$ \\
\hline${ }^{239} \mathrm{Pu}$ & $8,32 E+17$ & $1,07 \mathrm{E}+16$ & ${ }^{90} \mathrm{Sr}$ & $1,09 E+20$ & $2,85 E+01$ \\
\hline${ }^{240} \mathrm{Pu}$ & 1,4E+18 & $1,97 \mathrm{E}+16$ & ${ }^{93 \mathrm{~m}} \mathrm{Nb}$ & $7,93 E+15$ & $1,36 \mathrm{E}+01$ \\
\hline${ }^{241} \mathrm{Pu}$ & $4,2 E+19$ & $4,91 \mathrm{E}+17$ & ${ }^{93} \mathrm{Zr}$ & $8,12 E+15$ & $1,53 \mathrm{E}+06$ \\
\hline${ }^{241} \mathrm{Am}$ & $1,01 \mathrm{E}+19$ & $9,28 E+16$ & ${ }^{9 y} \mathrm{Tc}$ & $6,54 \mathrm{E}+16$ & $2,12 E+05$ \\
\hline${ }^{242} \mathrm{Pu}$ & $5,77 E+15$ & $4,33 E+13$ & ${ }^{10 /} \mathrm{Pd}$ & $5,83 \mathrm{E}+14$ & $6,50 \mathrm{E}+06$ \\
\hline${ }^{242 \mathrm{~m}} \mathrm{Am}$ & $1,95 E+16$ & $1,18 \mathrm{E}+16$ & ${ }^{121 \mathrm{~m}} \mathrm{Sn}$ & $7,81 \mathrm{E}+16$ & $5,50 \mathrm{E}+01$ \\
\hline${ }^{243} \mathrm{Am}$ & $5,84 \mathrm{E}+16$ & $5,8 E+14$ & ${ }^{126} \mathrm{Sn}$ & $3,04 \mathrm{E}+15$ & $1,00 E+05$ \\
\hline${ }^{243} \mathrm{Cm}$ & $1,69 \mathrm{E}+16$ & $1,72 \mathrm{E}+15$ & ${ }^{129} \mathrm{I}$ & $1,11 \mathrm{E}+14$ & $1,57 \mathrm{E}+07$ \\
\hline${ }^{244} \mathrm{Cm}$ & $1,52 E+18$ & $3,99 E+16$ & ${ }^{135} \mathrm{Cs}$ & $2,4 \mathrm{E}+15$ & $2,30 \mathrm{E}+06$ \\
\hline${ }^{245} \mathrm{Cm}$ & $1,14 \mathrm{E}+15$ & $2,6 E+13$ & ${ }^{137} \mathrm{Cs}$ & $1,8 \mathrm{E}+20$ & $3,02 E+01$ \\
\hline${ }^{246} \mathrm{Cm}$ & $1,97 \mathrm{E}+14$ & $3,29 E+12$ & ${ }^{151} \mathrm{Sm}$ & $1,25 E+18$ & $8,70 \mathrm{E}+01$ \\
\hline${ }^{247} \mathrm{Cm}$ & $6,78 E+08$ & & ${ }^{152} \mathrm{Eu}$ & $6,88 E+15$ & $1,24 \mathrm{E}+01$ \\
\hline${ }^{248} \mathrm{Cm}$ & 1,42E+09 & & ${ }^{154} \mathrm{Eu}$ & $3,72 \mathrm{E}+18$ & $8,50 \mathrm{E}+00$ \\
\hline${ }^{237} \mathrm{~Np}$ & $1,23 \mathrm{E}+15$ & $8,55 \mathrm{E}+12$ & ${ }_{166 \mathrm{~m}}^{158} \mathrm{~Tb}$ & $8,03 E+12$ & $1,80 \mathrm{E}+02$ \\
\hline${ }^{226} \mathrm{Ra}$ & $\begin{array}{l}3,38 E+15 \\
2,49 E+10\end{array}$ & $1,82 \mathrm{E}+13$ & & $3,82 E+13$ & $1,20 \mathrm{E}+03$ \\
\hline
\end{tabular}

Для оценки доз облучения населения будем рассматривать ситуацию с распределением радионуклидов из глубинного захоронения в столбе породы, образованном движением почвенной влаги от места захоронения до поверхности почвы. Будем также предполагать, что поверхности почвы достигнут радионуклиды, растворённые в воде. В этом случае удельная активность колодезной воды в поверхностном слое почвы (Бк/л) будет определяться выражением:

$$
A_{y \partial}=0,001 \cdot Q /\left(k_{r} \cdot \varepsilon \cdot V\right),
$$

где $\boldsymbol{Q}$ - общая активность радионуклидов в захоронении, Бк; $\boldsymbol{k}_{\boldsymbol{r}}$ - коэффицциент задержки, отн. ед.; $\boldsymbol{\varepsilon}$ - пористость почвы, отн. ед.; $\boldsymbol{V}$ - объём загрязнённой почвы, м ${ }^{3}$.

Удельная активность радионуклидов в почве (Бк/кг) за счёт их содержания в поровой воде равна:

$$
\begin{aligned}
& A_{\text {удпочвы }}=Q /\left(M \cdot k_{r}\right), \\
& k_{r}=\left[1+0,001\left(K_{d} \cdot \rho_{s} / \varepsilon\right)\right],
\end{aligned}
$$

где $\boldsymbol{M}$ - масса породы, через которую промигрировали радионуклиды, кг; $\boldsymbol{K}_{\boldsymbol{d}}-$ коэфффициент распределения, л/кг; $\rho_{s}$ - плотность почвы, кг/м³. Численные коэффрициенты в фрормулах (1) и (3) введены для соответствия единиц измерения. 
Предполагаем, что глубинное захоронение располагается на глубине 1 км. Площадь размещения отходов примем $10^{4} \mathrm{~m}^{2}$. После разрушения инженерных барьеров радионуклиды вместе с поровой водой перемещаются к поверхности почвы. Скорость движения воды к поверхности примем равной 1 см в сутки [20]. При этих условиях с учётом движения в горизонтальной плоскости поровая вода до выхода к поверхности почвы займет объём $3,5 \cdot 10^{9} \mathrm{~m}^{3}$. При плотности почвы 1600 кг/м ${ }^{3}$ масса столба породы, в котором будут равномерно распределены растворённые в воде радионуклиды, составит $5,6 \cdot 10^{12}$ кг.

Движение воды к поверхности с такой скоростью займет примерно 270 лет. Если предположить, что инженерные барьеры безопасности хранения отходов сохранят свои свойства в течение, по крайней мере, 300 лет, загрязнение поверхностного слоя почвы может произойти примерно через 600 лет. Процесс выщелачивания из матрицы отходов в принятых приближениях не учитывается.

На основе данных об удельной активности будут рассчитаны дозы внешнего и внутреннего облучения населения при проживании на территории с таким загрязнением. При этом предполагается, что все необходимые продукты питания производятся на этой территории. Другой сценарий облучения связан с потреблением воды из скважины в месте выхода радионуклидов на поверхность почвы.

Значения коэфффициентов распределения, а также дозовые коэффиициенты внешнего и внутреннего облучения взрослого населения представлены в табл. 2 и 3. Таблицы включают данные для нуклидов из цепочек распада актиноидов.

Таблица 2

Коэфффициенты распределения нуклидов для глинистой породы

\begin{tabular}{|c||c||c||c|}
\hline \hline Нуклид & $\boldsymbol{K}_{\boldsymbol{d}}$, л/кг & Нуклид & $\boldsymbol{K}_{\boldsymbol{d}}$, л/кг \\
\hline \hline $\mathrm{Cm}$ & 19000 & $\mathrm{Zr}$ & 1000 \\
$\mathrm{Pu}$ & 950 & $\mathrm{Nb}$ & 1000 \\
$\mathrm{U}$ & 110 & $\mathrm{Tc}$ & 5 \\
$\mathrm{Th}$ & 18000 & $\mathrm{Pd}$ & 1000 \\
$\mathrm{Ra}$ & 38000 & $\mathrm{Sn}$ & 1000 \\
$\mathrm{Am}$ & 4200 & $\mathrm{I}$ & 10 \\
$\mathrm{~Pa}$ & 2700 & $\mathrm{Cs}$ & 1000 \\
$\mathrm{~Np}$ & 38 & $\mathrm{Sm}$ & 1000 \\
$\mathrm{Ac}$ & 2400 & $\mathrm{~Tb}$ & 1000 \\
$\mathrm{Se}$ & 1000 & $\mathrm{Ho}$ & 1000 \\
$\mathrm{Sr}$ & 1000 & & \\
\hline
\end{tabular}

Таблица 3

Коэффициенты дозового преобразования внешнего и внутреннего облучения, приведённые к удельной активности радионуклидов в почве 1 Бк/кг

\begin{tabular}{|c|c|c|c|c|c|}
\hline Нуклид & $\begin{array}{c}\text { КДП внешнее, } \\
\text { мкЗв/год }\end{array}$ & $\begin{array}{c}\text { КДП внутреннее, } \\
\text { мкЗв/год }\end{array}$ & Нуклид & $\begin{array}{c}\text { КДП внешнее, } \\
\text { мкЗв/год }\end{array}$ & $\begin{array}{c}\text { КДП внутреннее, } \\
\text { мкЗв/год }\end{array}$ \\
\hline${ }^{225} \mathrm{Ac} \ldots+{ }^{209} \mathrm{~Pb}$ & $2,19 E-01$ & 6,53E-04 & $\begin{array}{c}{ }^{228} \mathrm{Th} \ldots+0,64^{212} \mathrm{Po}+ \\
+036^{208} \mathrm{Pl}\end{array}$ & $2,20 \mathrm{E}+00$ & 1,13E-02 \\
\hline${ }^{221} \mathrm{Ac}$ & $1,54 \mathrm{E}-04$ & 2,99E-02 & ${ }_{222}^{229}$ & $1,00 \mathrm{E}-01$ & $7,68 \mathrm{E}-02$ \\
\hline${ }^{241} \mathrm{Am}$ & $2,01 \mathrm{E}-02$ & 1,69E-03 & ${ }^{230} \mathrm{Th}$ & 4,09E-04 & $3,29 \mathrm{E}-02$ \\
\hline${ }^{242} \mathrm{Am}$ & $1,80 \mathrm{E}-02$ & $0,00 \mathrm{E}+00$ & ${ }^{32} \mathrm{Th}$ & & 3,61E-02 \\
\hline${ }^{242 \mathrm{~m}} \mathrm{Am}$ & $2,38 \mathrm{E}-04$ & 1,61E-03 & $234 \mathrm{Th}+{ }^{234 \mathrm{~m}} \mathrm{~Pa}$ & $2,35 E-02$ & 5,33E-04 \\
\hline${ }^{243} \mathrm{Am}+{ }^{239} \mathrm{~Np}$ & $2,16 \mathrm{E}-01$ & 1,69E-03 & & & 2,88E-02 \\
\hline${ }^{242} \mathrm{Cm}$ & & 7,68E-04 & 4 & $3,26 \mathrm{E}-04$ & 2,77E-02 \\
\hline${ }^{433} \mathrm{Cm}$ & 1,43E-01 & $9,60 \mathrm{E}-03$ & $\mathrm{U}_{+}^{2}$ & $2,14 \mathrm{E}-01$ & 2,66E-02 \\
\hline $244 \mathrm{Cm}$ & & 7,68E-03 & & & 2,66E-02 \\
\hline${ }^{45} \mathrm{Cm}$ & $1,32 \mathrm{E}-01$ & 1,34E-02 & ${ }^{38} \mathrm{U}$ & $1,98 \mathrm{E}-04$ & 2,54E-02 \\
\hline${ }^{246} \mathrm{Cm}$ & $0,00 \mathrm{E}+00$ & 1,34E-02 & ${ }^{9} \mathrm{Se}$ & & 2,97E-01 \\
\hline${ }^{247} \mathrm{Cm}+{ }^{243} \mathrm{Pu}$ & 4,85E-01 & 1,22E-02 & 喿 $\mathrm{Sr}+{ }^{90} \mathrm{Y}$ & & $1,90 \mathrm{E}+00$ \\
\hline $\mathrm{Cm}$ & & 4,93E-02 & $\mathrm{Nb}$ & 9,04E-03 & 9,45E-04 \\
\hline
\end{tabular}


Продолжение таблицы 3

\begin{tabular}{|c|c|c|c|c|c|}
\hline Нуклид & $\begin{array}{c}\text { КДП внешнее, } \\
\text { мкЗв/год }\end{array}$ & $\begin{array}{c}\text { КДП внутреннее, } \\
\text { мкЗв/год }\end{array}$ & Нуклид & $\begin{array}{c}\text { КДП внешнее, } \\
\text { мкЗв/год }\end{array}$ & $\begin{array}{c}\text { КДП внутреннее, } \\
\text { мкЗв/год }\end{array}$ \\
\hline $\begin{array}{c}{ }^{237} \mathrm{~Np} \\
{ }^{231} \mathrm{~Pa} \\
{ }^{233} \mathrm{~Pa} \\
{ }^{210} \mathrm{~Pb}^{210} \mathrm{Bi} \\
{ }^{210} \mathrm{Po} \\
{ }^{238} \mathrm{Pu} \\
{ }^{239} \mathrm{Pu} \\
{ }^{240} \mathrm{Pu} \\
{ }^{241} \mathrm{Pu} \\
{ }^{242} \mathrm{Pu} \\
{ }^{244} \mathrm{Pu}+{ }^{240} \mathrm{U}_{+}^{240 \mathrm{~m}} \mathrm{~Np} \\
{ }^{223} \mathrm{Ra} \ldots+.{ }^{207} \mathrm{TI} \\
{ }^{225} \mathrm{Ra} \\
{ }^{226}{ }^{22} \mathrm{Ra} \ldots+{ }^{214} \mathrm{Po} \\
{ }^{228} \mathrm{Ra}+{ }^{228} \mathrm{Ac} \\
{ }^{22 \prime} \mathrm{Th}\end{array}$ & $\begin{array}{l}2,60 \mathrm{E}-02 \\
3,91 \mathrm{E}-02 \\
2,56 \mathrm{E}-01 \\
1,28 \mathrm{E}-03 \\
\\
\\
\\
\\
\\
4,56 \mathrm{E}-01 \\
4,20 \mathrm{E}-01 \\
5,11 \mathrm{E}-03 \\
2,73 \mathrm{E}+00 \\
1,28 \mathrm{E}+00 \\
6,64 \mathrm{E}-02\end{array}$ & $\begin{array}{l}9,57 \mathrm{E}-02 \\
1,93 \mathrm{E}-02 \\
1,96 \mathrm{E}-05 \\
6,75 \mathrm{E}-01 \\
1,22 \mathrm{E}+00 \\
9,14 \mathrm{E}-04 \\
9,94 \mathrm{E}-04 \\
9,94 \mathrm{E}-04 \\
1,91 \mathrm{E}-05 \\
9,54 \mathrm{E}-04 \\
9,54 \mathrm{E}-04 \\
1,77 \mathrm{E}-01 \\
1,75 \mathrm{E}-01 \\
4,96 \mathrm{E}-01 \\
1,22 \mathrm{E}+00 \\
1,38 \mathrm{E}-03\end{array}$ & $\begin{array}{l}{ }^{93} \mathrm{Zr} \\
{ }^{99} \mathrm{Tc} \\
{ }^{107} \mathrm{Pd} \\
{ }^{121 \mathrm{~m}} \mathrm{Sn} \\
{ }^{126} \mathrm{Sn} \\
{ }^{12 y} \mathrm{I} \\
{ }^{135} \mathrm{Cs} \\
{ }^{13 /} \mathrm{Cs} \\
{ }^{151} \mathrm{Sm} \\
{ }^{152} \mathrm{Eu} \\
{ }^{154} \mathrm{Eu} \\
{ }^{158} \mathrm{~Tb} \\
{ }^{166 \mathrm{~m}} \mathrm{Ho}\end{array}$ & $\begin{array}{l}4,90 \mathrm{E}-02 \\
3,00 \mathrm{E}-03 \\
9,19 \mathrm{E}-03 \\
\\
8,35 \mathrm{E}-01 \\
3,40 \mathrm{E}-04 \\
1,27 \mathrm{E}+00 \\
1,32 \mathrm{E}+00 \\
5,63 \mathrm{E}-01 \\
2,22 \mathrm{E}+00\end{array}$ & $\begin{array}{l}1,33 \mathrm{E}-04 \\
3,28 \mathrm{E}-01 \\
5,33 \mathrm{E}-04 \\
1,20 \mathrm{E}-04 \\
2,30 \mathrm{E}-01 \\
3,91 \mathrm{E}-01 \\
3,03 \mathrm{E}-02 \\
1,03 \mathrm{E}-01 \\
2,47 \mathrm{E}-05 \\
2,86 \mathrm{E}-04 \\
4,64 \mathrm{E}-04 \\
2,28 \mathrm{E}-04 \\
3,59 \mathrm{E}-04\end{array}$ \\
\hline
\end{tabular}

Расчёт годовой эфффективной дозы облучения при потреблении радионуклидов с колодезной водой проводили с помощь дозовых коэффрициентов из работы [28]. Потребление воды составляло 1 л в сутки.

В результате расчётов доз облучения населения в сценарии с выходом радионуклидов из глубинного захоронения растворимой части всех накопленных долгоживущих высокоактивных отходов в вариантах развития ядерной энергетики с тепловыми (TP) и тепловыми с быстрыми (ТР+БР) реакторами представлены на рис. 1.

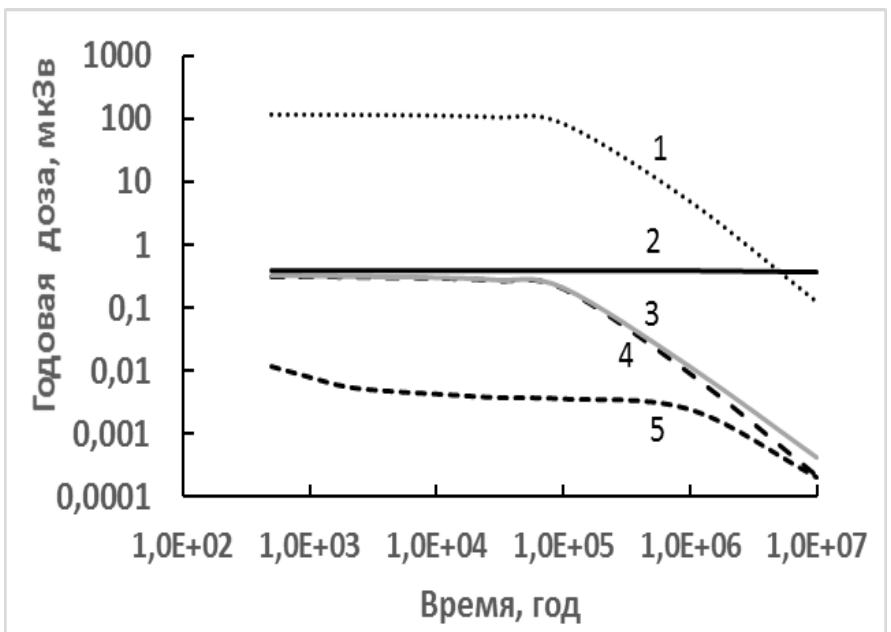

Рис. 1. Потенциальная годовая эффективная доза населения от радионуклидов, вышедших в разное время на поверхность почвы из глубинного захоронения отходов ядерной энергетики. 1 - доза облучения от отходов ядерной энергетики на тепловых реакторах; 2 - доза облучения от природного урана; 3 - доза облучения от отходов ядерной энергетики на тепловых и быстрых реакторах; 4 - вклад в дозу от продуктов деления отходов при использовании тепловых и быстрых реакторов; 5 - вклад в дозу от актиноидов при использовании тепловых и быстрых реакторов.

Из рисунка видно, что доза облучения от загрязнённой почвы в случае захоронения отходов ядерной энергетики на основе только ТР примерно в 100 раз больше дозы от отходов ядерной энергетики с использованием ТР+БР в замкнутом топливном цикле. При этом доза облучения от отходов ТР+БР меньше 1 мкЗв в год и меньше доз от всего природного урана, использованного для изготовления топлива на 2100 г. Кроме того, установлено, что при выходе 
радионуклидов на поверхность почвы доза облучения без учёта потребления воды из колодцев в месте выхода практически полностью до времени $10^{7}$ лет фрормируется от долгоживущих продуктов деления.

В случае потребления воды из колодца на месте выхода радионуклидов из глубинного захоронения доза облучения населения значительно выше доз от загрязнённой почвы для обоих вариантов развития ядерной энергетики (рис. 2). Вклад продуктов деления в дозу облучения населения значительно меньше вклада от актиноидов, в отличие от сценария с загрязнённой почвой (рис. 3). Это объясняется тем, что расчёт доз проводится по удельной активности воды и почвы, а поровой воды в килограмме почвы содержится в 6,5 раза меньше по массе. Кроме этого, за счёт малых коэффициентов перехода радионуклидов в пищевые цепочки через растения доза от почвы уменьшается в десятки и более раз (в зависимости от радионуклида). Особенно малы коэффициенты перехода в растения у актиноидов, поэтому в варианте с миграцией по почве основными источниками облучения становятся продукты деления.

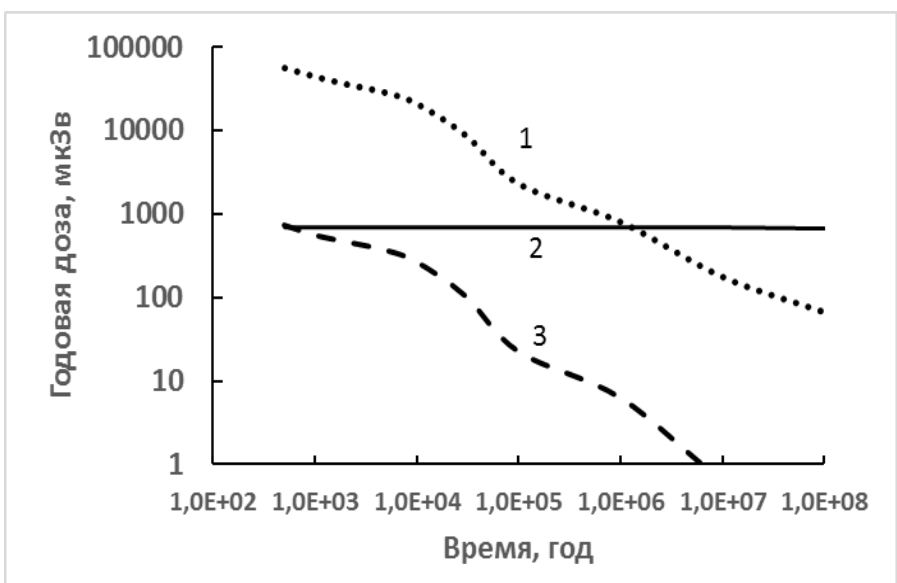

Рис. 2. Доза облучения населения от потребления воды из колодца над глубинным захоронением.

1 - доза облучения от отходов ядерной энергетики на тепловых реакторах; 2 - доза облучения от природного урана; 3 - доза облучения от отходов ядерной энергетики на тепловых и быстрых реакторах.

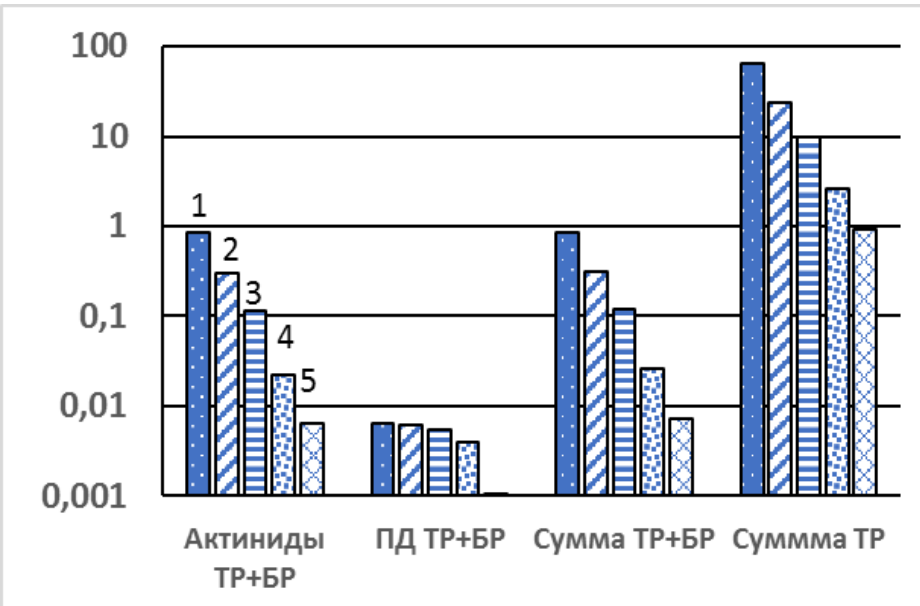

Рис. 3. Вклад в дозу облучения от потребления радионуклидов с колодезной водой от актиноидов и продуктов делений относительно радионуклидов из использованного природного урана на разные времена после захоронения.

1 - 500 лет после захоронения; $2-10^{4}$ лет; $3-3 \cdot 10^{4}$ лет; $4-10^{5}$ лет; $5-10^{6}$ лет. 
Таким образом, оценка потенциальной опасности глубинного захоронения по сценарию с потреблением колодезной воды должна иметь приоритет перед сценарием с загрязнением почвы. Кроме того, полученные результаты показывают, что производимые ранее [10-12] оценки потенциальной биологической опасности долгоживущих высокоактивных отходов по радиотоксичности наиболее адекватны, поскольку учитывают наибольший вклад актиноидов в дозу облучения человека.

Полученные результаты не претендуют на то, чтобы быть окончательным обоснованием опасности или безопасности глубинного захоронения РАО. Они не учитывают ряд факторов, связанных с характеристиками инженерных барьеров, свойствами матриц, в которые помещают отходы, физико-химическими свойствами геологической породы, особенностями распространения радионуклидов и т.д. Понятно, что все эти факторы, безусловно, являются источниками неопределённостей. Вместе с тем применение одинаковой технологии оценки доз облучения позволяет сделать объективный сравнительный анализ безопасности по различным сценариям облучения.

\section{Радиологические риски и радиологическая миграционная эквивалентность}

В 1954 г. через 9 лет после атомной бомбардировки в 1945 г. городов Хиросима и Нагасаки было принято решение о создании регистра «хибакуси» (лиц, переживших бомбардировку) численностью 92 тыс. человек (когорта LSS). В 1979 г. НКДАР ООН ввёл первую метрику радиационного риска (Зв) на основе эпидемиологических данных по когорте «хибакуси». В 2007 г. были выпущены рекомендации Международной комиссии по радиологической защите (МКРЗ) [29], которые уточнили оценку радиологических последствий облучения человека в терминах величины пожизненного атрибутивного риска индукции онкологических заболеваний (LAR, Lifetime Attributable Risk). В этом документе особо подчёркивалось (п. 197), что «дозы в органах и тканях, а не эффективные дозы требуются для оценки вероятности индукции рака у облучённых индивидуумов». Рассмотрим кратко технологию MKP3 по оценке величины LAR.

На сегодняшний день на международном уровне анализом последствий действия ионизирующего облучения занимаются несколько организаций. Одной из них является МКРЗ. Эта организация в своей Публикации 103 [29] предложила математические модели для оценки радиационных рисков, основанные в основном на наблюдениях за когортой LSS. Особенностью этих моделей является принятие концепции линейной беспороговой модели, т.е. модели оценки зависимости «доза-эффрект», предполагающей, что в диапазоне малых доз риск развития рака, вызванный облучением, прямо пропорционален дозе этого облучения.

Чтобы оценить радиологические последствия для здоровья человека в конкретной популяции, в Публикации 103 МКР3 [29] рекомендуется рассчитывать значение пожизненного атрибутивного риска (LAR) с использованием моделей риска, основанных на заболеваемости, для различных локализаций солидных раков и модели риска для лейкемии [30]. Внутреннее облучение требует также учёта риска развития рака кости, для которого модель МКРЗ отсутствует. Для этой локализации в данной работе используются модели, предложенные НКДАР ООН [31].

Пусть $\lambda_{0}$ - показатель фроновой заболеваемости злокачественными новообразованиями $(3 \mathrm{HO})$ или смертности от них (отношение числа случаев за один год к полному числу лиц, находящихся под наблюдением за этот год). Воздействие радиации приводит к увеличению $\lambda_{0}$ на 
некоторую дополнительную величину $\delta \lambda$. Согласно МКР3 [29] радиогенный риск $\delta \lambda$ математически может быть представлен в виде двух форм: аддитивной и мультипликативной. В аддитивной форме EAR не зависит от фоновой заболеваемости, т.е. $\delta \lambda=E A R$, где $E A R$ - это избыточный абсолютный риск (от англ. Excess Absolute Risk). В мультипликативной модели $\delta \lambda=\lambda_{0} \cdot \boldsymbol{E} \boldsymbol{R}$, где

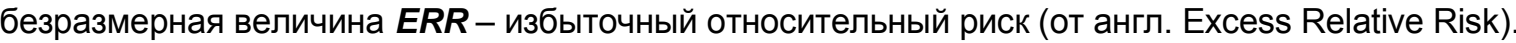

Два этих подхода в определении величины $\delta \lambda$ дают разный численный результат для популяций, отличных от тех, на которых строились модели радиационного риска. В этом случае МКР3 [29] рекомендует вычислять $\delta \lambda$ как взвешенную сумму аддитивного и мультипликативного подходов. Величина $\delta \lambda$ зависит от пола, локализации новообразования, возраста при облучении, дозы облучения, возраста, на который ведётся расчёт (возраст дожития).

Пожизненный атрибутивный риск (LAR) характеризует количество избыточных над фоновым числом раковых заболеваний или смертей, которые могут произойти в течение всей последующей жизни после облучения группы лиц, у которых одинаковы модифицирующие риск факторы (пол, возраст при облучении и др.). LAR смертности от ЗНО вычисляется путём суммирования $\delta \lambda$ с весом вероятности дожития и доли летальности от заданной локализации опухоли по всем возможным возрастам дожития.

Внутреннее облучение человека характеризуется длительным облучением организма. После попадания определённого радионуклида или радионуклидного состава в организм в возрасте $\boldsymbol{e}_{0}$, динамика ежегодных эквивалентных доз $\boldsymbol{H}_{T}\left(\boldsymbol{e}-\boldsymbol{e}_{0}\right)$ в конкретном органе или ткани $\boldsymbol{T}$ с течением времени $\boldsymbol{t}=\boldsymbol{e}-\boldsymbol{e}_{0}$ может быть получена из базы данных МКРЗ дозовых коэфффициентов [32]. При ежегодном поступлении радионуклидов в организм эти облучения накладываются друг на друга. Подробно описание моделей MKP3 [29] для расчёта EAR и ERR, а также методики вычисления LAR от внутреннего облучения при однократном поступлении в организм человека заданного радионуклида уже было ранее опубликовано [33]. При многократном поступлении радионуклидов в организм итоговый LAR будет суммой LAR от отдельных ежегодных поступлений. Для расчёта значений LAR в данной работе используются официальные медико-демографрические статистические данные о населении России [34].

Ha pис. 4, 5 приведены значения LAR, отражающие радиационный риск онкосмертности от глубинного захоронения отходов ядерной энергетики (ТР, ТР+БР) для двух сценариев облучения: пожизненное ежегодное облучение от рождения до смерти и облучение в течение 1 года в возрасте 20 лет. Можно сделать три основных вывода.

Bo-первых, величина LAR от TP+БР ниже значения LAR от природного урана, т.е. после достижения радиологической эквивалентности (100 лет выдержки) [2] наблюдается на всём интервале времени (до $10^{9}$ лет) выполнение условий радиологической миграционной эквивалентности.

Bo-вторых, LAR от TP+БР для ситуаций пожизненного облучения (рис. 4) и облучения в течение 1 года (рис. 5) в 100 раз ниже «пренебрежимо малого» по действующему в НРБ99/2009 уровня $\left(10^{-6}\right)$.

B-третьих, величина LAR для TP в 350 раз больше величины LAR для TP+БР, причём для достижения радиологической миграционной эквивалентности в этом случае необходимо более 1 млн лет после захоронения (рис. 4). 


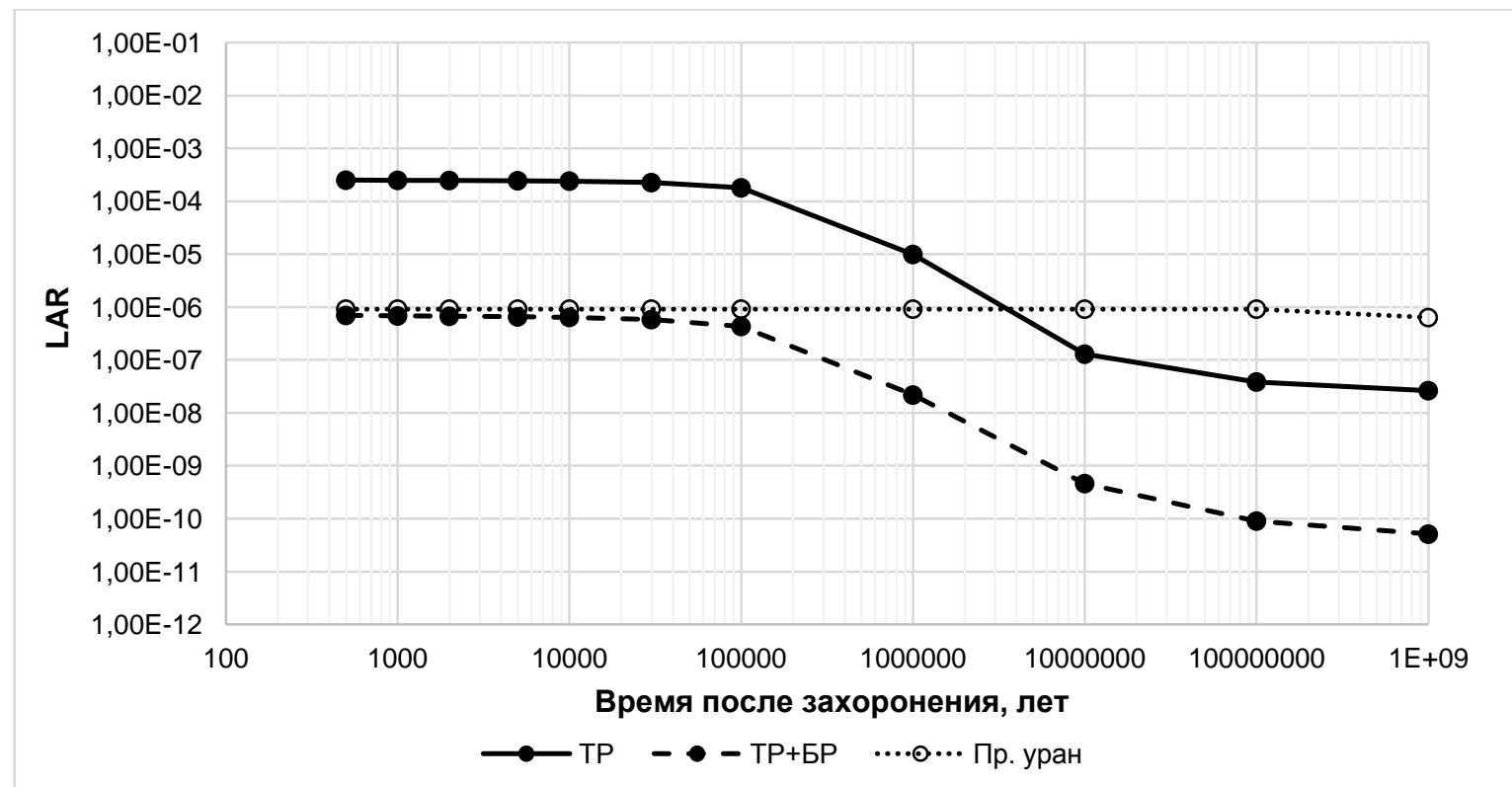

Рис. 4. Пожизненный атрибутивный риск (LAR) онкосмертности от глубинного захоронения отходов ядерной энергетики, основанной на использовании тепловых реакторов (TP), тепловых и быстрых реакторов (ТР+БР) и природного урана от радионуклидов, вышедших в разное время на поверхность почвы при проживании в районе захоронения от рождения и до смерти.

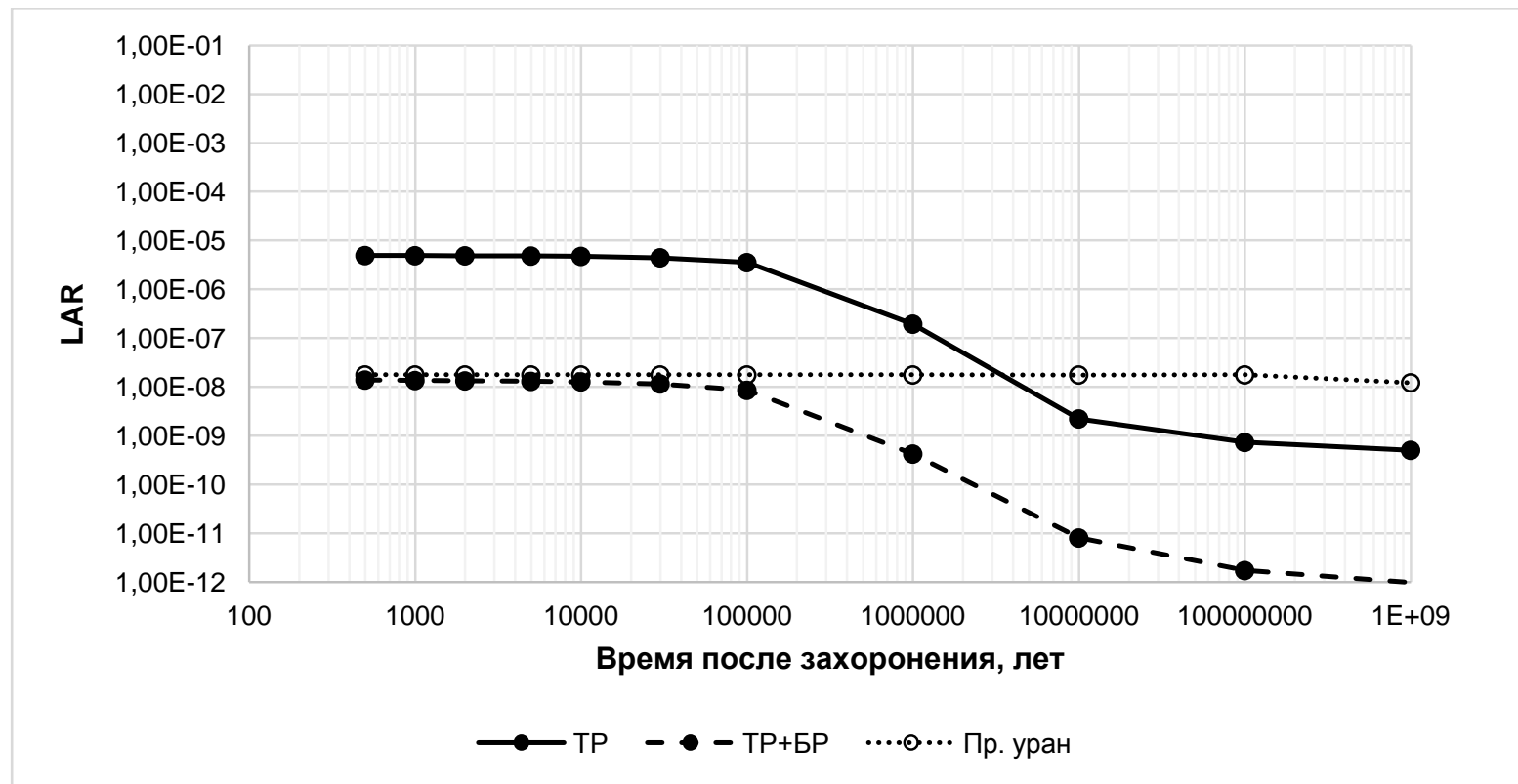

Рис. 5. Пожизненный атрибутивный риск (LAR) онкосмертности от глубинного захоронения отходов ядерной энергетики, основанной на использовании тепловых реакторов (TP), тепловых и быстрых реакторов (ТР+БР) и природного урана от радионуклидов, вышедших в разное время на поверхность почвы при проживании в районе захоронения в течение 1 года в возрасте 20 лет.

На рис. 6, 7 даны значения LAR для TP и TP+БР при потреблении воды из колодца за всю жизнь или 1 год. Легко заметить, что основные выводы, сделанные на основе данных, показанных на рис. 4, 5, сохраняются. Однако LAR для ТP+БР (рис. 6) имеет максимальное значение уже $10^{-3}$, что на три порядка больше LAR для TP+БР (рис. 4). Вместе с тем, это значение $\left(10^{-3}\right)$ соответствует требованиям НРБ-99/2009 $\left(5 \cdot 10^{-5}\right)$ с учётом пожизненного (100 лет) облучения. 
Пожизненный атрибутивный риск (LAR) для TP в 100 раз выше, чем для TP+БР, для достижения радиологической миграционной эквивалентности (рис. 6, 7) требуется более 100 тыс. лет после захоронения.

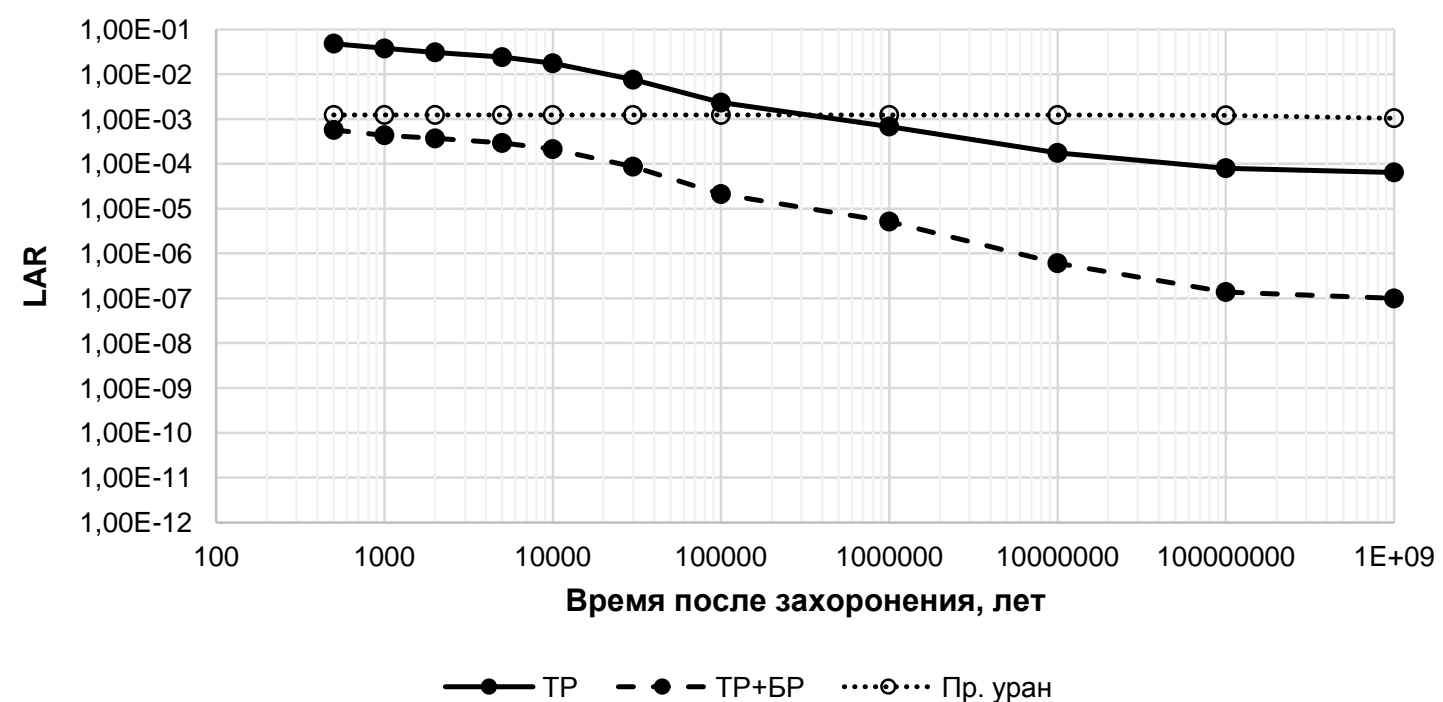

Рис. 6. Пожизненный атрибутивный риск (LAR) онкосмертности от глубинного захоронения отходов ядерной энергетики, основанной на использовании тепловых реакторов (TP), тепловых и быстрых реакторов (ТР+БР) и природного урана от потребления воды из колодца при проживании в районе захоронения от рождения и до смерти.

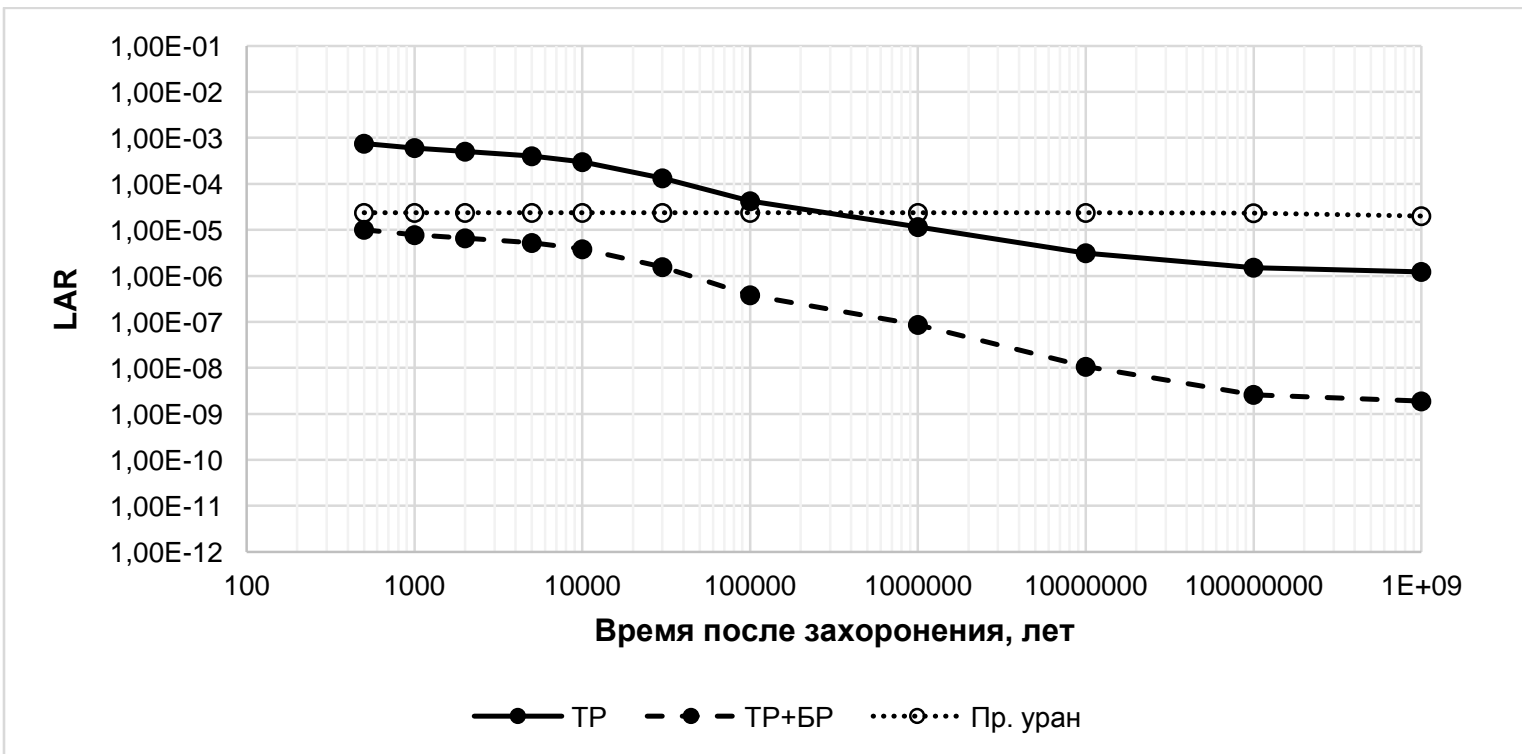

Рис. 7. Пожизненный атрибутивный риск (LAR) онкосмертности от глубинного захоронения отходов ядерной энергетики, основанной на использовании тепловых реакторов (TP), тепловых и быстрых реакторов (ТР+БР) и природного урана от потребления воды из колодца при проживании в районе захоронения в течение 1 года в возрасте 20 лет.

На рис. 8-14 показан вклад основных радионуклидов (в \%) в пожизненный атрибутивный риск (LAR) при различных сценариях облучения (природный уран, TP, TP+БР). Так, из рис. 8 следует, что более $50 \%$ в величину риска от природного урана даёт внешнее облучение. Существенный вклад в риск (почти $30 \%$ ) также вносит радионуклид ${ }^{210} \mathrm{Po}$. 


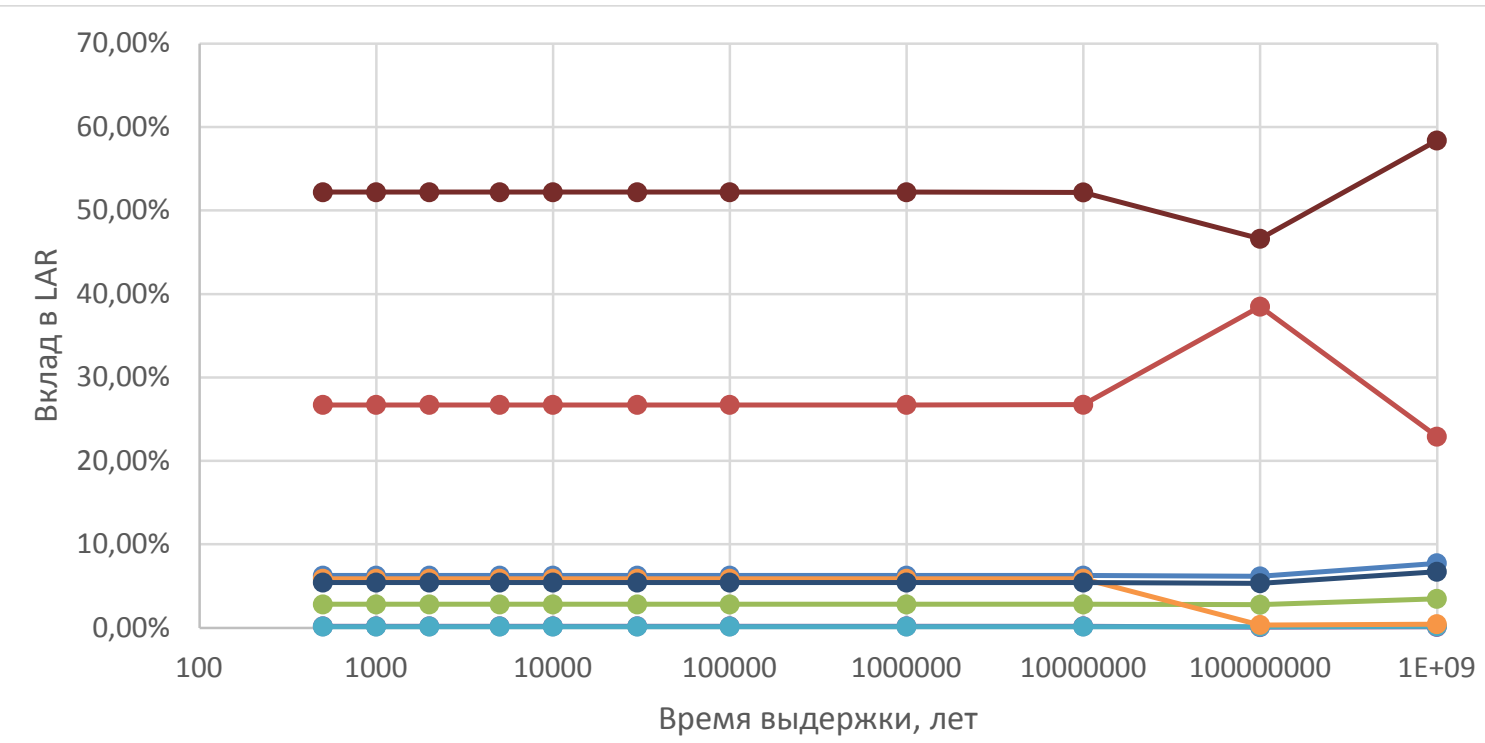

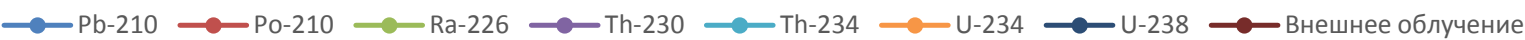

Рис. 8. Вклад в LAR различных источников при облучении от глубинного захоронения природного урана от радионуклидов, вышедших в разное время на поверхность почвы.

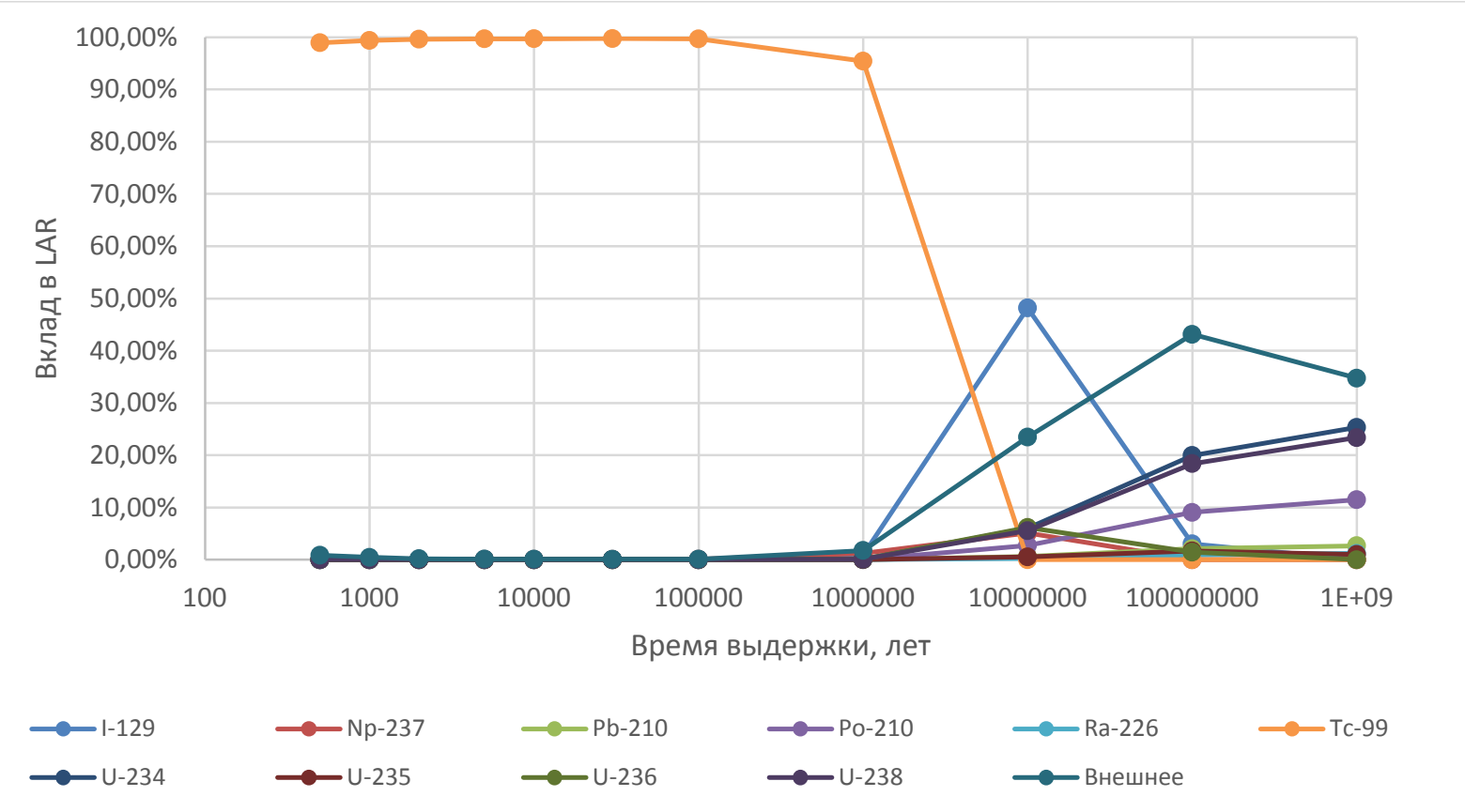

Рис. 9. Вклад в LAR различных источников при облучении от глубинного захоронения отходов ядерной энергетики, основанной на использовании тепловых реакторов, от радионуклидов, вышедших в разное время на поверхность почвы. 


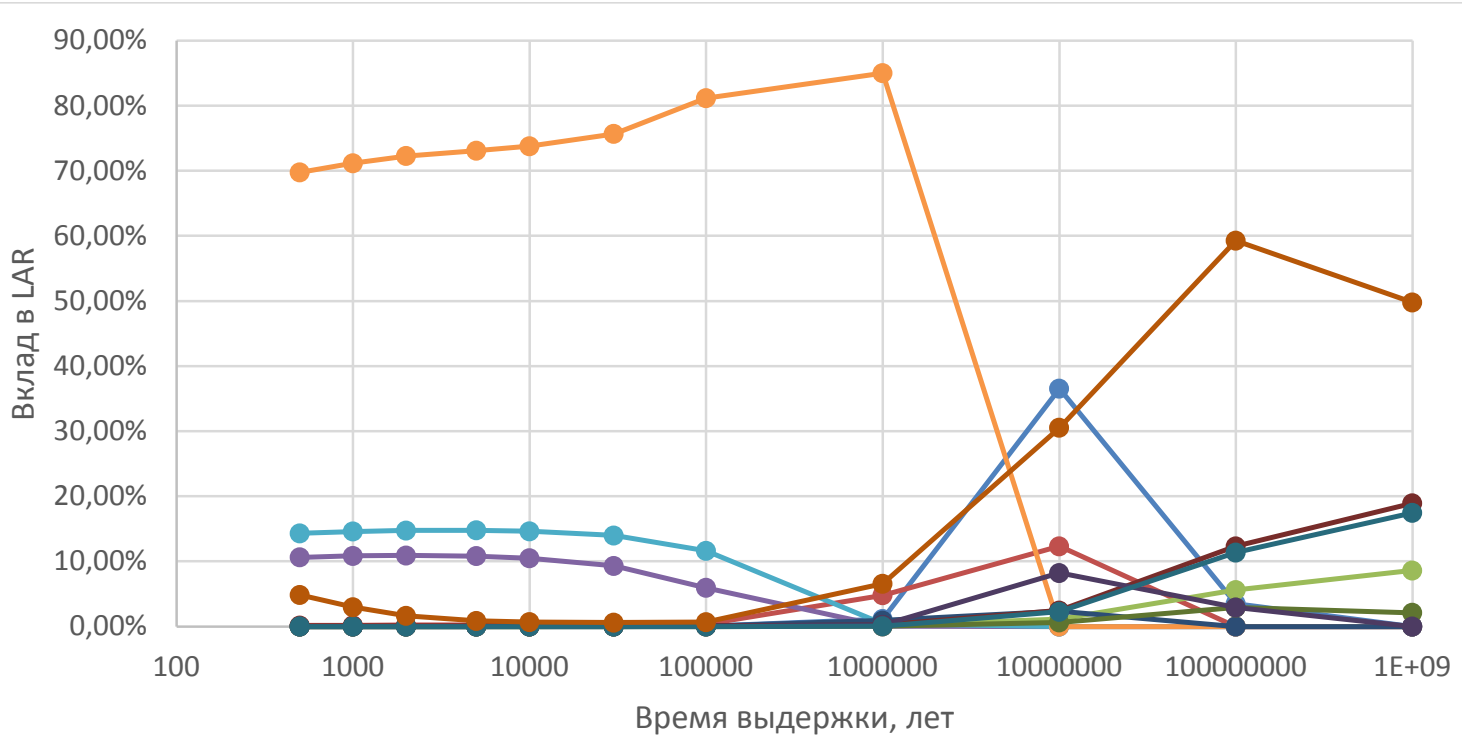

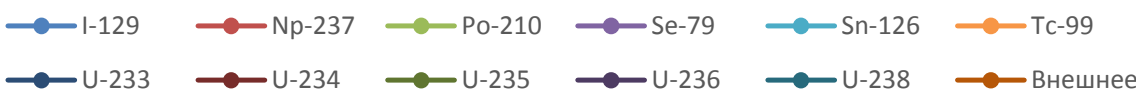

Рис. 10. Вклад в LAR различных источников при облучении от глубинного захоронения отходов ядерной энергетики, основанной на использовании тепловых и быстрых реакторов, от радионуклидов, вышедших в разное время на поверхность почвы.

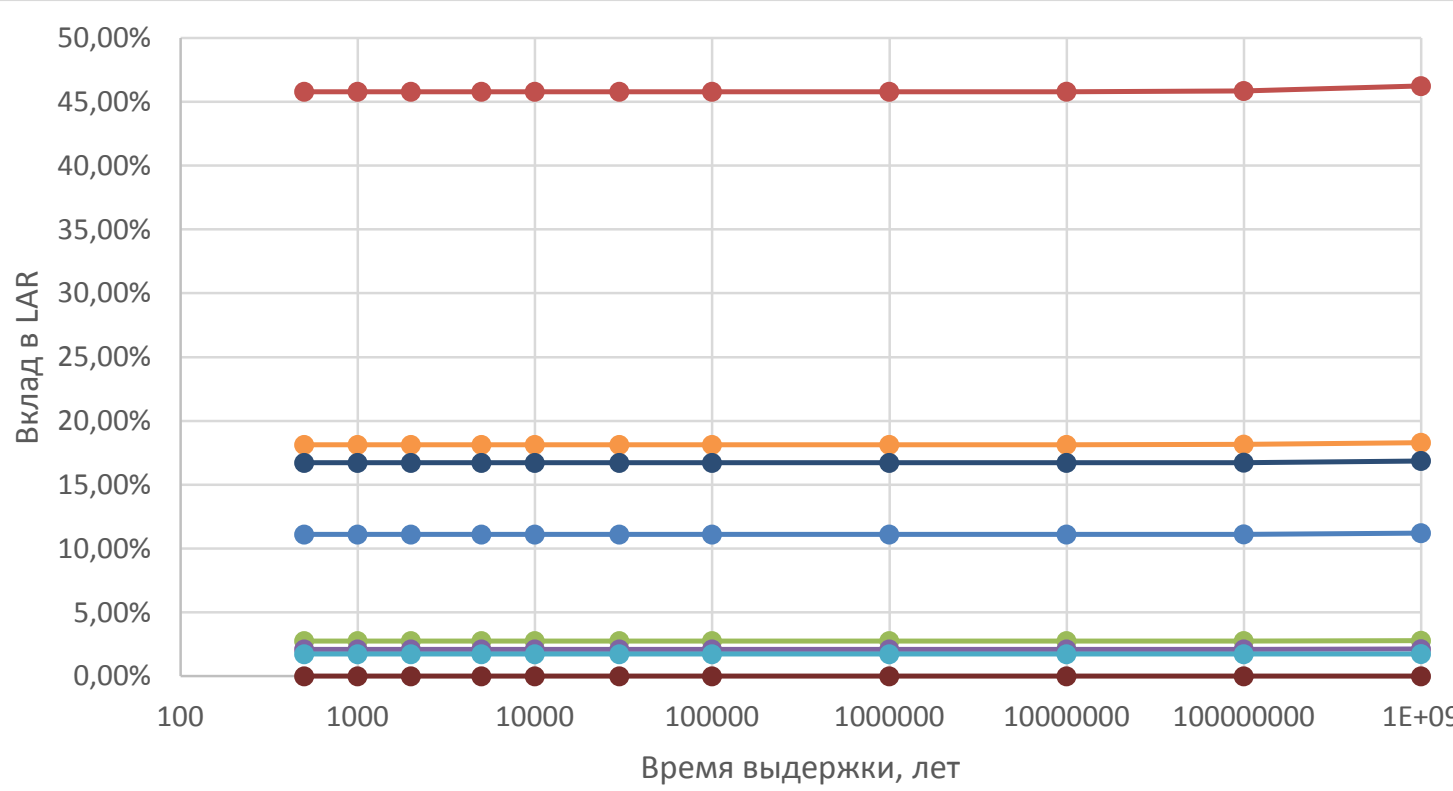

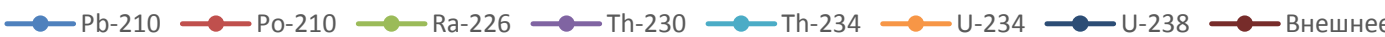

Рис. 11. Вклад в LAR различных источников при облучении от глубинного захоронения природного урана от потребления воды из колодца над глубинным захоронением. 


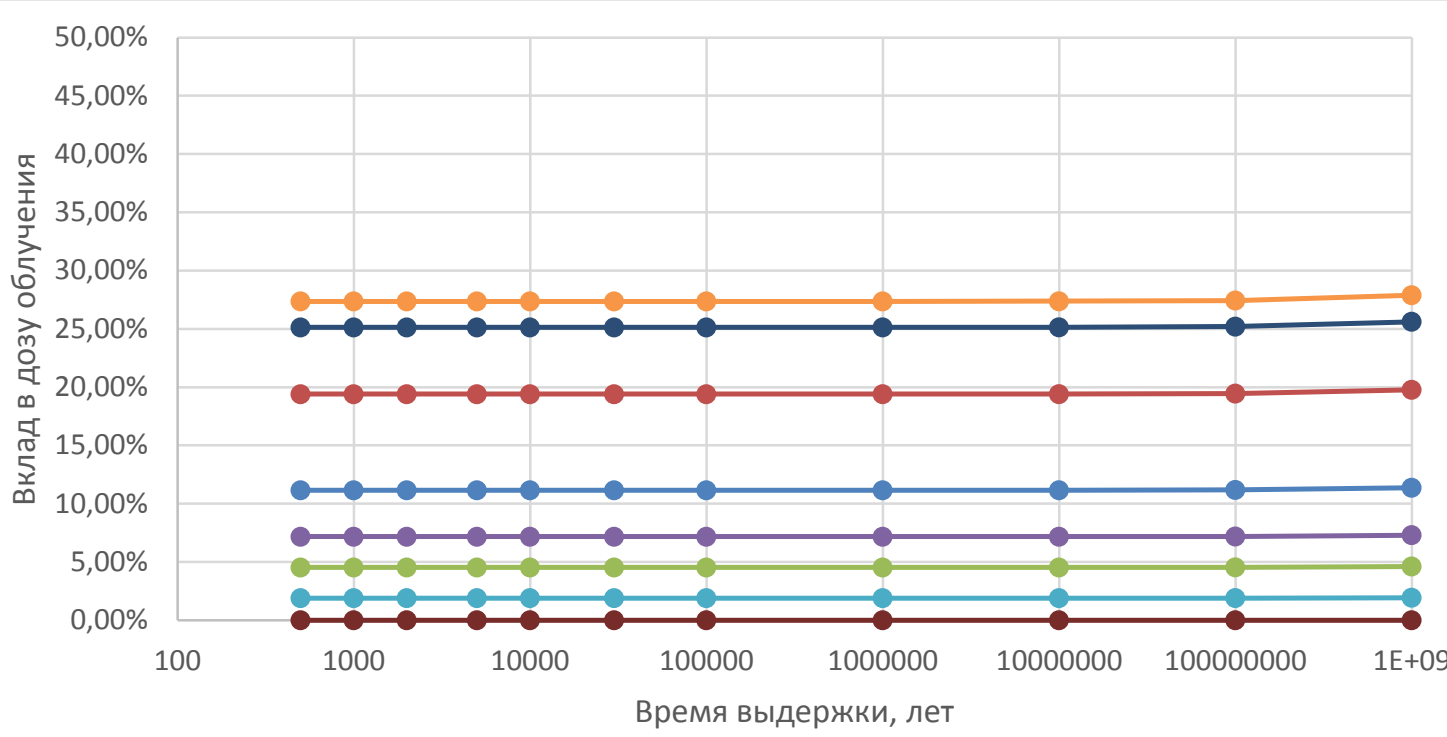

$\begin{array}{lll}\longrightarrow \text { Pb-210 } & \longrightarrow \text { Po-210 } & \longrightarrow \text { Th-230 } \\ \longrightarrow \text { Th-234 } & \longrightarrow \text { T-234 } & \longrightarrow \text { - }\end{array}$

Рис. 12. Вклад в дозу различных источников при облучении от глубинного захоронения природного урана от потребления воды из колодца над глубинным захоронением.

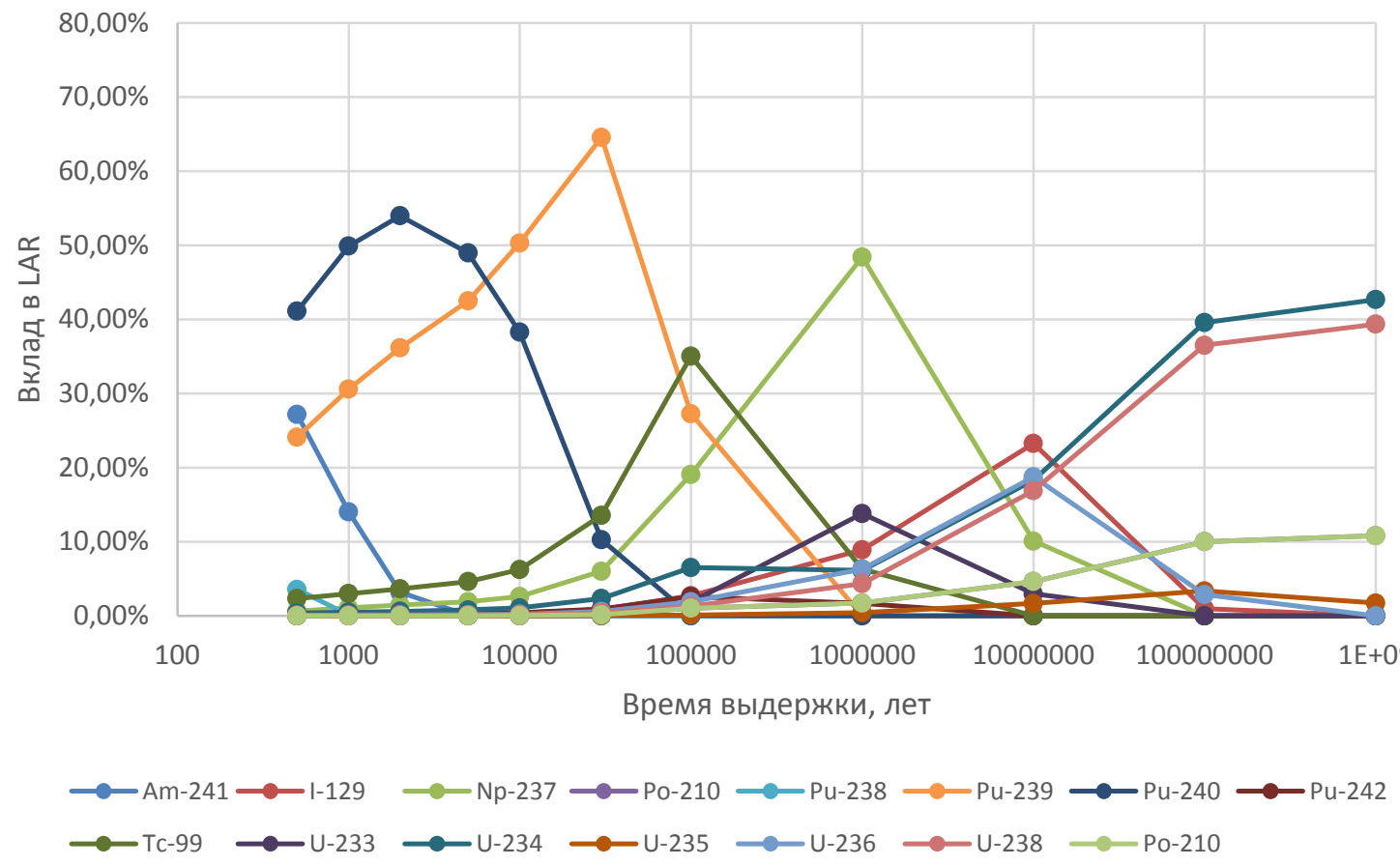

Рис. 13. Вклад в LAR различных источников при облучении от глубинного захоронения отходов ядерной энергетики, основанной на использовании тепловых реакторов от потребления воды из колодца над глубинным захоронением. 


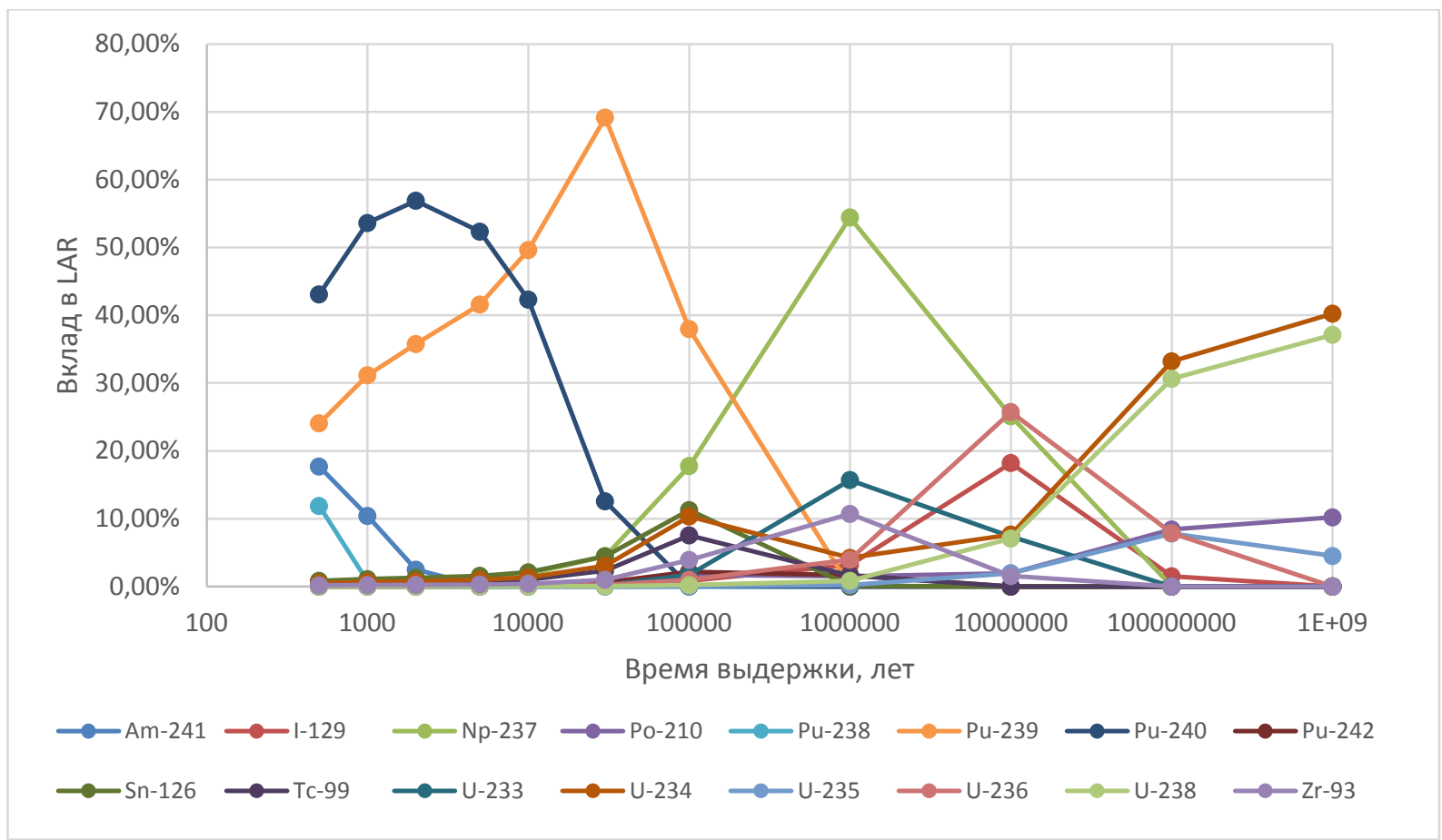

Рис. 14. Вклад в LAR различных источников при облучении от глубинного захоронения отходов ядерной энергетики, основанной на использовании тепловых и быстрых реакторов, от потребления воды из колодца над глубинным захоронением.

Подавляющий вклад в LAR от TP (рис. 9) вносит ${ }^{99} \mathrm{Tc}$, период полураспада которого превышает 100 тыс. лет. Величина LAR от ТР+БР (рис. 10) определяется в основном ${ }^{99} \mathrm{Tc}$, а также ${ }^{126} \mathrm{Sn}$ и ${ }^{79} \mathrm{Se}$. При потреблении из колодцев воды после захоронения природного урана (рис. 11) основными риск-образующими радионуклидами являются ${ }^{210} \mathrm{Po},{ }^{234} \mathrm{U},{ }^{210} \mathrm{~Pb}$.

На рис. 12 показан для этой ситуации облучения вклад радионуклидов в дозу. Как видно из рис. 11,12 , имеет место принципиальное отличие основных радионуклидов по вкладу в LAR и по вкладу в дозу. Поэтому понятно требование МКРЗ оценивать канцерогенный риск по величине LAR, а не по величине ожидаемой эффрективной дозы.

На рис. 13, 14 показан вклад различных радионуклидов в LAR при потреблении воды из колодцев с учётом отходов ТР и ТР+БР. Важно отметить доминирующую роль ${ }^{241} \mathrm{Am} n{ }^{239} \mathrm{Pu}$ как основных, определяющих радиологический риск радионуклидов на интервале до 10 тыс. лет после захоронения.

Как видно из рис. 15,16 , эквивалентные дозы ${ }^{210} \mathrm{Po} и{ }^{234} \mathrm{U}$ имеют разное распределение по органам. В случае ${ }^{210}$ Ро максимальные эквивалентные дозы приходятся на печень, другие солидные раки и лейкозы. Именно эти органы имеют максимальный риск на единицу дозы. 


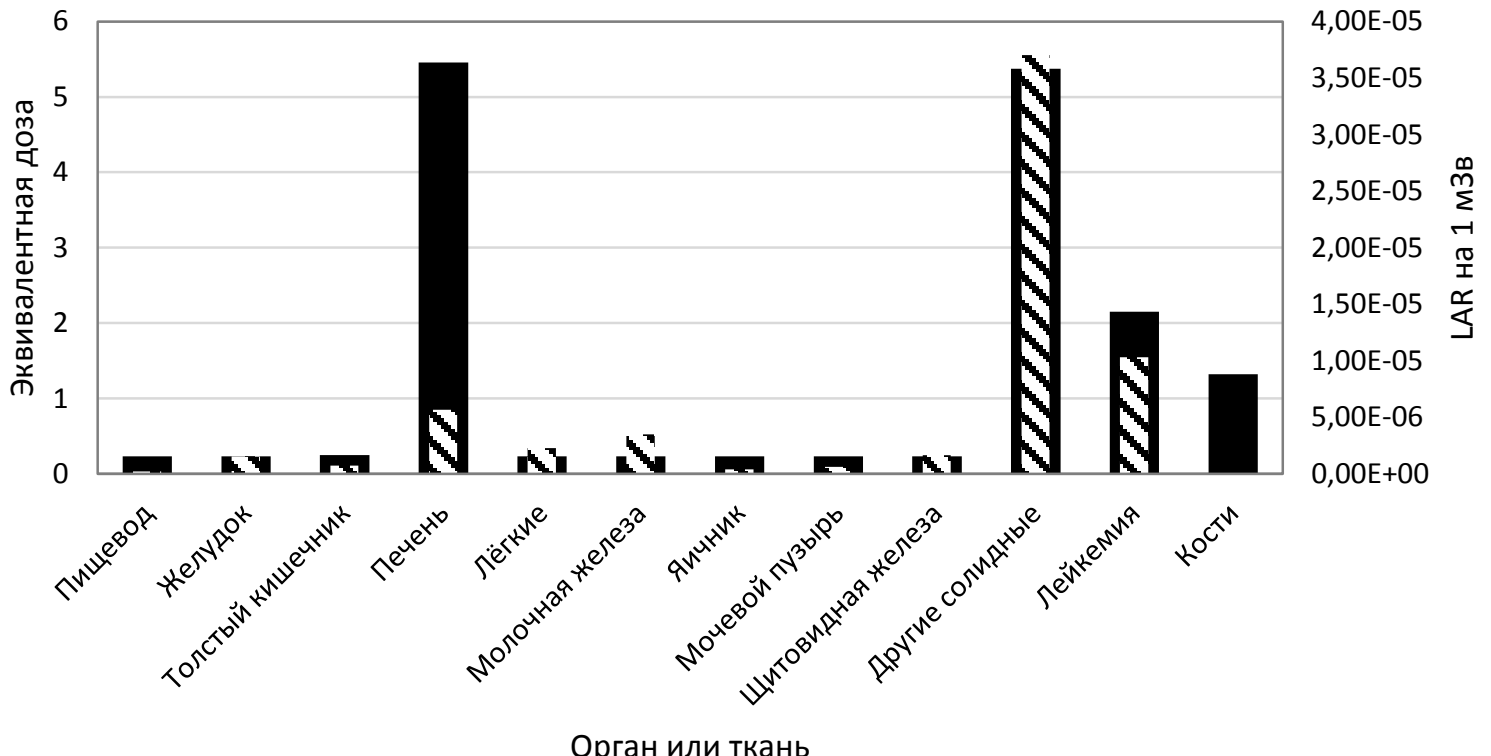

Эквивалентная доза V LAR на 1 м3в

Рис. 15. Распределение эквивалентных доз и пожизненных атрибутивных рисков заболеваемости раком среди женского населения (возраст - 0-100 лет) при внутреннем облучении от радионуклида ${ }^{210} \mathrm{Po}$, поступающего с пищей, с ожидаемой эффективной дозой, равной 1 мЗв.

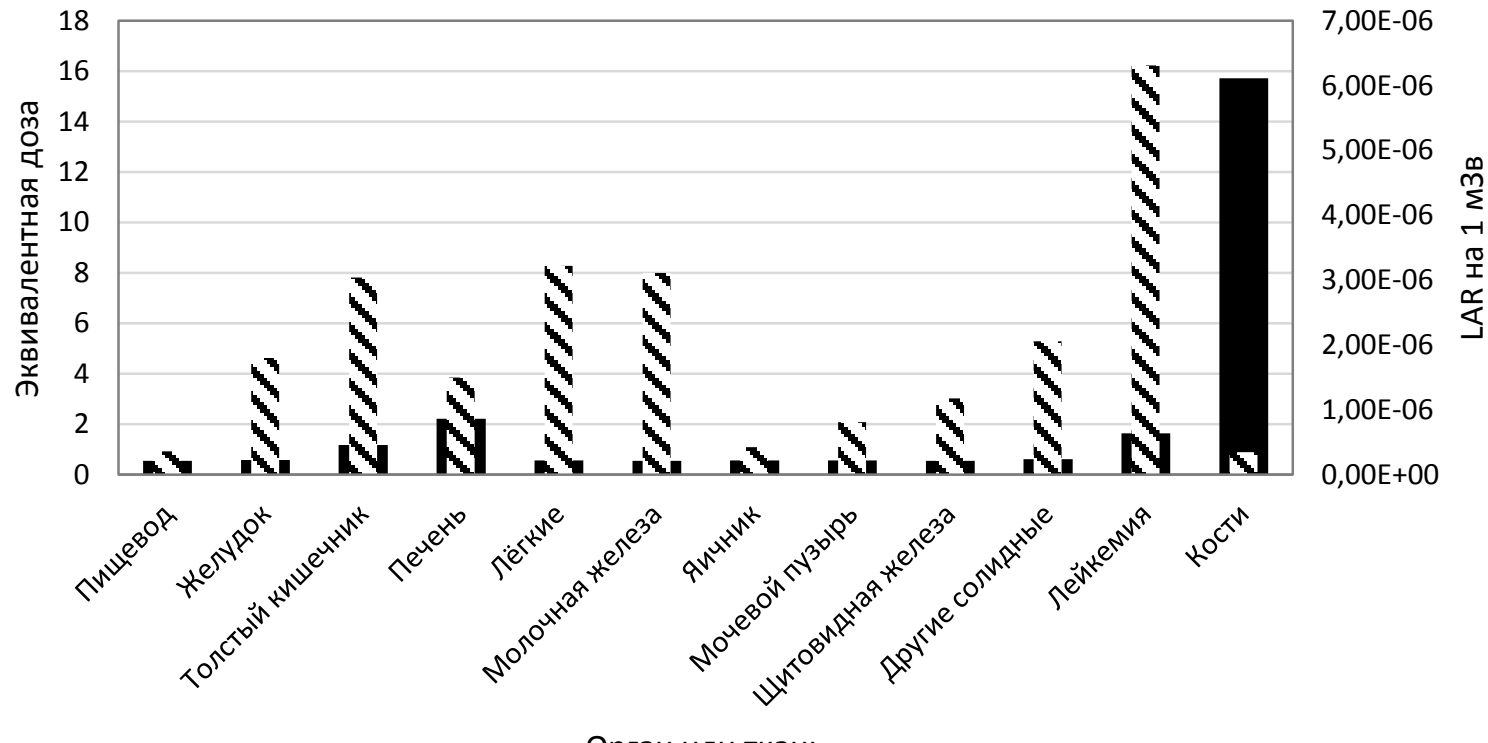

Орган или ткань

• Эквивалентная доза VLAR на 1 м3в

Рис. 16. Распределение эквивалентных доз и пожизненных атрибутивных рисков заболеваемости раком среди женского населения (возраст - 0-100 лет) при внутреннем облучении от радионуклида ${ }^{234} U$, поступающего с пищей, с ожидаемой эффективной дозой, равной 1 мЗв. 
Как было отмечено выше, величина пожизненного атрибутивного риска LAR при выходе радионуклидов из глубинного захоронения TP в 350 раз больше величины LAR при TP+БP.

Для наиболее полной количественной оценки вредного воздействия радиации на здоровье человека, в частности, в разных частях его тела, МКРЗ [23] вводит многомерную концепцию радиационного ущерба (radiation detriment), одним из главных компонентов которого является LAR. Однако, формулы для вычисления радиационного ущерба, приведённые в последних рекомендациях MKP3 [23], используют номинальные коэффрициенты риска, т.е. величины LAR на единицу дозы, рассчитанные для стандартной популяции МКРЗ. В общем случае, для заданной конкретной популяции или для узкой половозрастной группы лиц необходимо использовать локализованные для этой популяции, или группы лиц, величины LAR и другие компоненты ущерба. Соответствующее обобщение формул МКРЗ [23] приведено в работе Иванова В.К. и соавторов [35], где определяется величина «радиологического ущерба» (РАУ) для произвольной группы лиц:

$$
P A Y=L A R \cdot F(q, l, k),
$$

где $\boldsymbol{q}$ - уровень снижения качества жизни; $\boldsymbol{I}$ - средняя потеря времени жизни; $\boldsymbol{k}$ - доля летальности.

Следует отметить, что в англоязычных источниках $[16,29]$ прилагательные «radiation» и «radiological», по определению словаря МАГАТЭ [36] являются синонимами, в то время как в русскоязычной литературе [1-3, 10-12] исторически сложилось различие в применении понятий «радиационный» и «радиологический», где последнее считается более общим [3, 35].

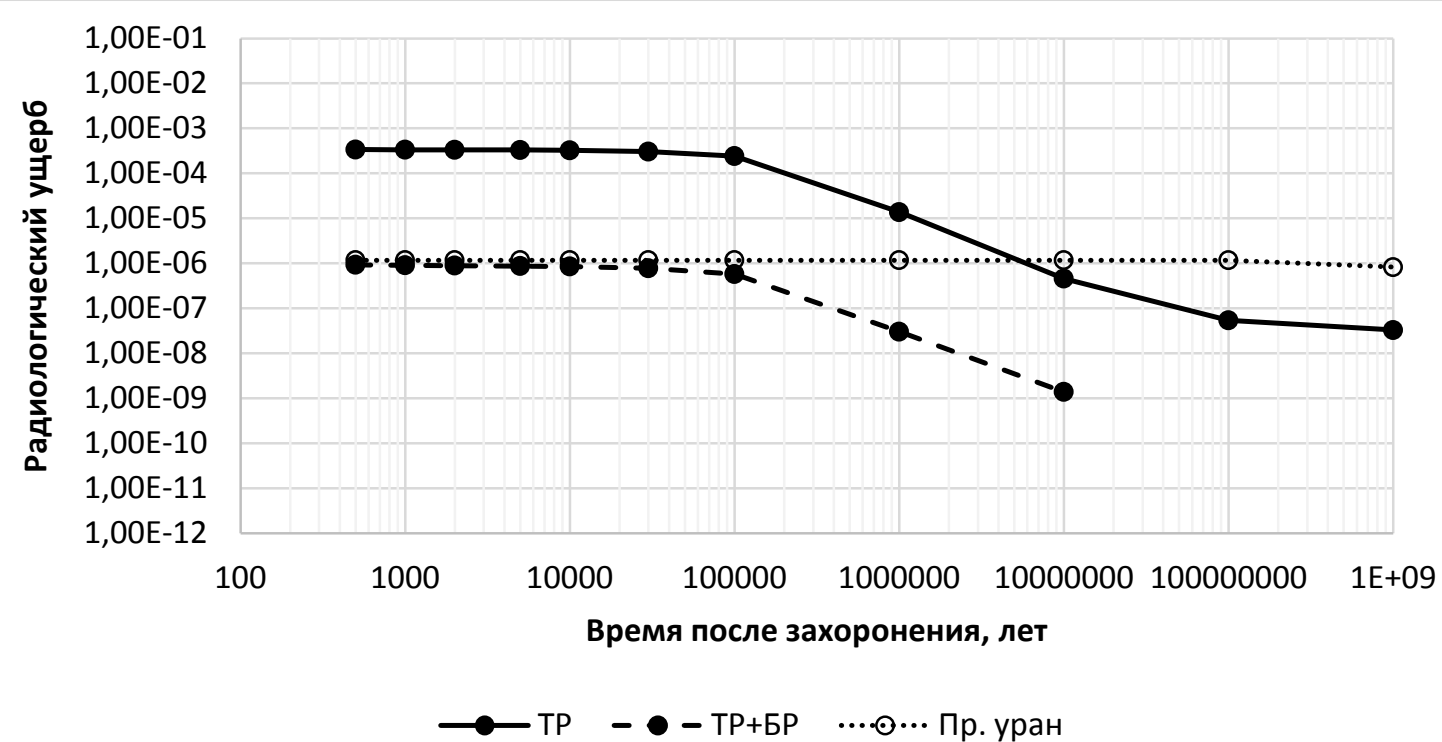

Рис. 17. Радиологический ущерб от глубинного захоронения отходов ядерной энергетики, основанной на использовании тепловых реакторов (ТP), тепловых и быстрых реакторов (ТР+БР) и глубинного захоронения природного урана от радионуклидов, вышедших в разное время на поверхность почвы при проживании в районе захоронения от рождения и до смерти. 


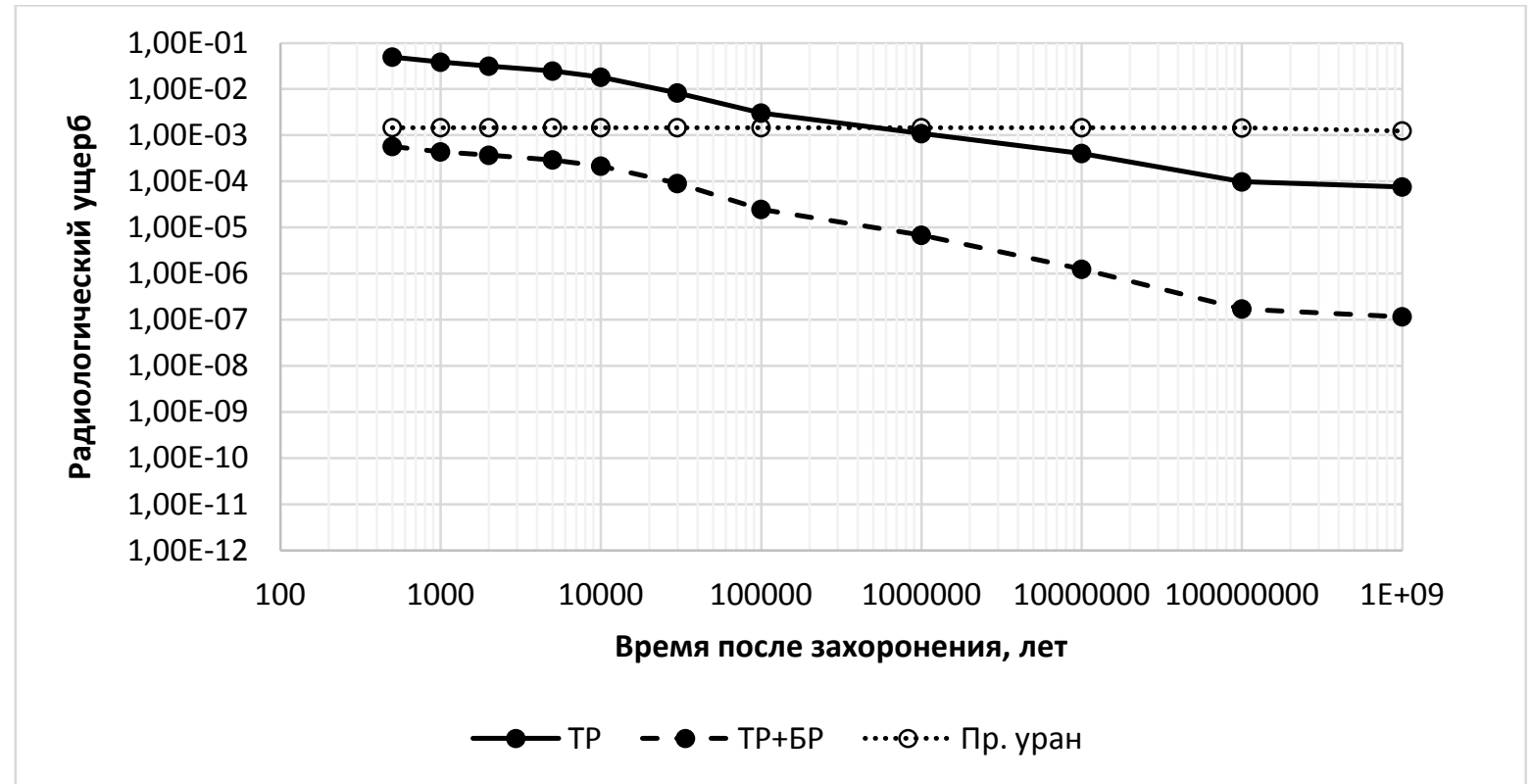

Рис. 18. Радиологический ущерб от глубинного захоронения отходов ядерной энергетики, основанной на использовании тепловых реакторов (ТР), тепловых и быстрых реакторов (ТР+БР) и глубинного захоронения природного урана от потребления воды из колодца при проживании в районе захоронения от рождения и до смерти.

На рис. 17, 18 показаны значения РАУ для сценариев без потребления и с потреблением колодезной воды. Как видно из указанных рисунков, величина РАУ для ТР+БР ниже значения РАУ для природного урана. Однако для сценария ТР величина РАУ многократно (на два с половиной порядка) выше соответствующего значения РАУ для природного урана и поэтому не является социально приемлемой для населения.

Эксперты НМИЦ онкологии им. Н.Н. Петрова совместно с учёными Университета Тампяре (Финляндия) и Международного агентства по изучению рака ВОЗ показали, что экономические потери РФ в результате преждевременной смертности россиян от онкозаболеваний составляют 8,1 млрд долларов в год (около 0,24\% ВВП). Было также установлено, что экономические потери в результате онкозаболеваний в разных странах примерно одинаковы и составляют 0,1-0,5\% ВВП [37].

В Энергетической стратегии РФ на период до 2035 года (Распоряжение Правительства РФ от 9 июня 2020 г. № 1523-р) подчёркивается, что «основные проблемы и риски развития атомной энергетики связаны со сравнительно высокими затратами на обеспечение ядерной и радиационной безопасности и с необходимостью обращения с отработавшим ядерным топливом и РАО с учётом требований экологической безопасности».

На pис. 6 даны значения величины LAR для TP и TP+БР при потреблении воды из колодца после выхода радионуклидов из глубинного захоронения. Величина LAR для TP+БP соответствует современным требованиям НРБ-99/2009. Однако величина LAR для TP существенно превышает эти требования. Так, на рис. 19 показано ожидаемое число радиационнообусловленных смертей от ЗНО, а на рис. 20 - их доля среди всех случаев онкологической смертности. Как видно из рис. 21, например, через 1500 лет после захоронения отходов ЯЭ, основанной на использовании ТР, ожидается 58490 радиационно-обусловленных случаев смерти от онкозаболеваний, что составляет $17,57 \%$ (рис. 20) от всех случаев онкопатологии. 
С учётом того, что экономические потери в случае одной онкосмертности составляют 2,11 млн руб., легко оценить, что итоговые экономические потери через 1500 лет после захоронения отходов ЯЭ, основанной на использовании ТР, превысят 123 млрд руб. Понятно, что при захоронении отходов ЯЭ, основанной на использовании ТР+БР, радиологический ущерб будет исключён. Как видно из рис. 21, величина радиологического ущерба отходов ЯЭ, основанной на использовании ТР, драматически возрастает с увеличением временного интервала после захоронения.

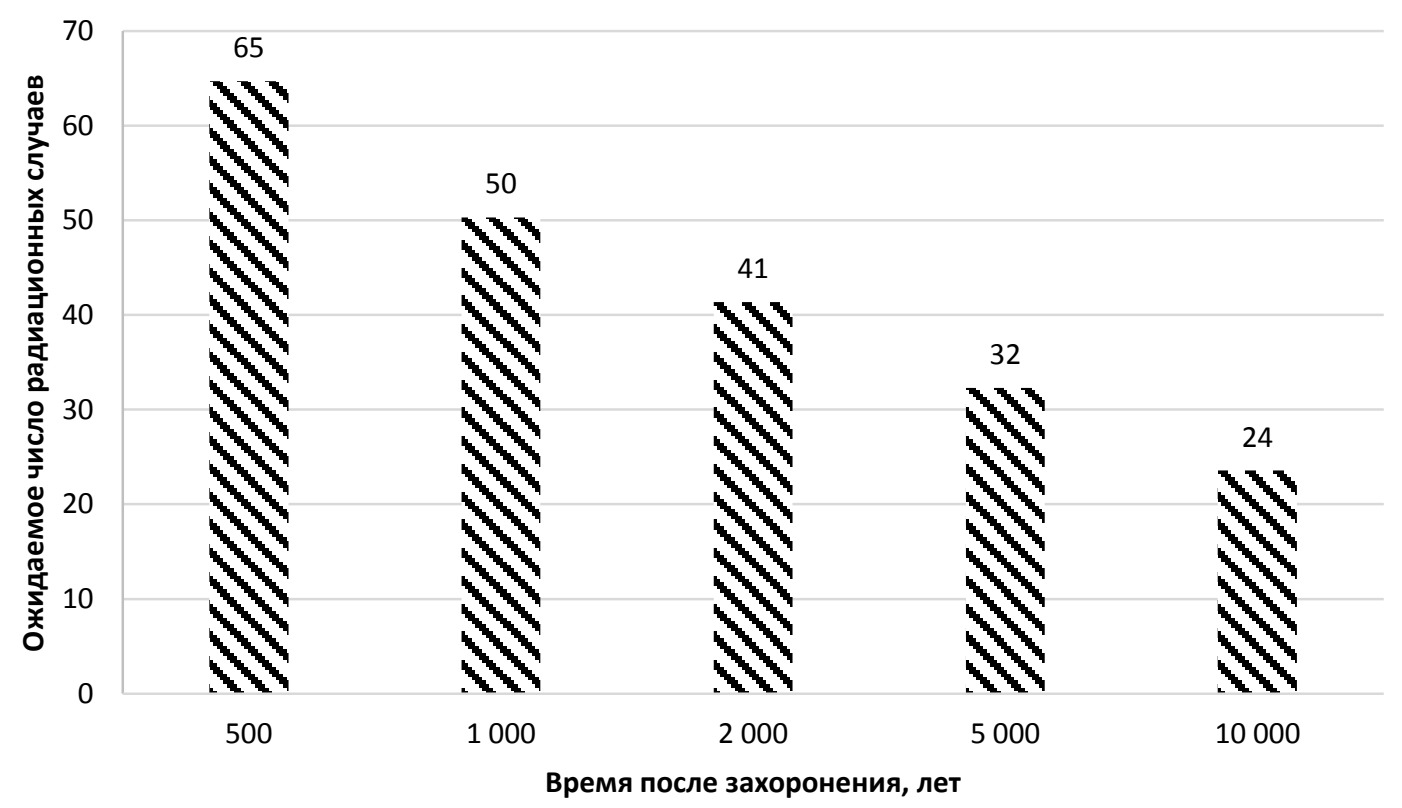

Рис. 19. Ожидаемое число радиационно-обусловленных случаев смерти от ЗНО в год в статической популяции численностью 100000 человек, при проживании в течение всей жизни в районе захоронения отходов ЯЭ, основанной на использовании ТР.

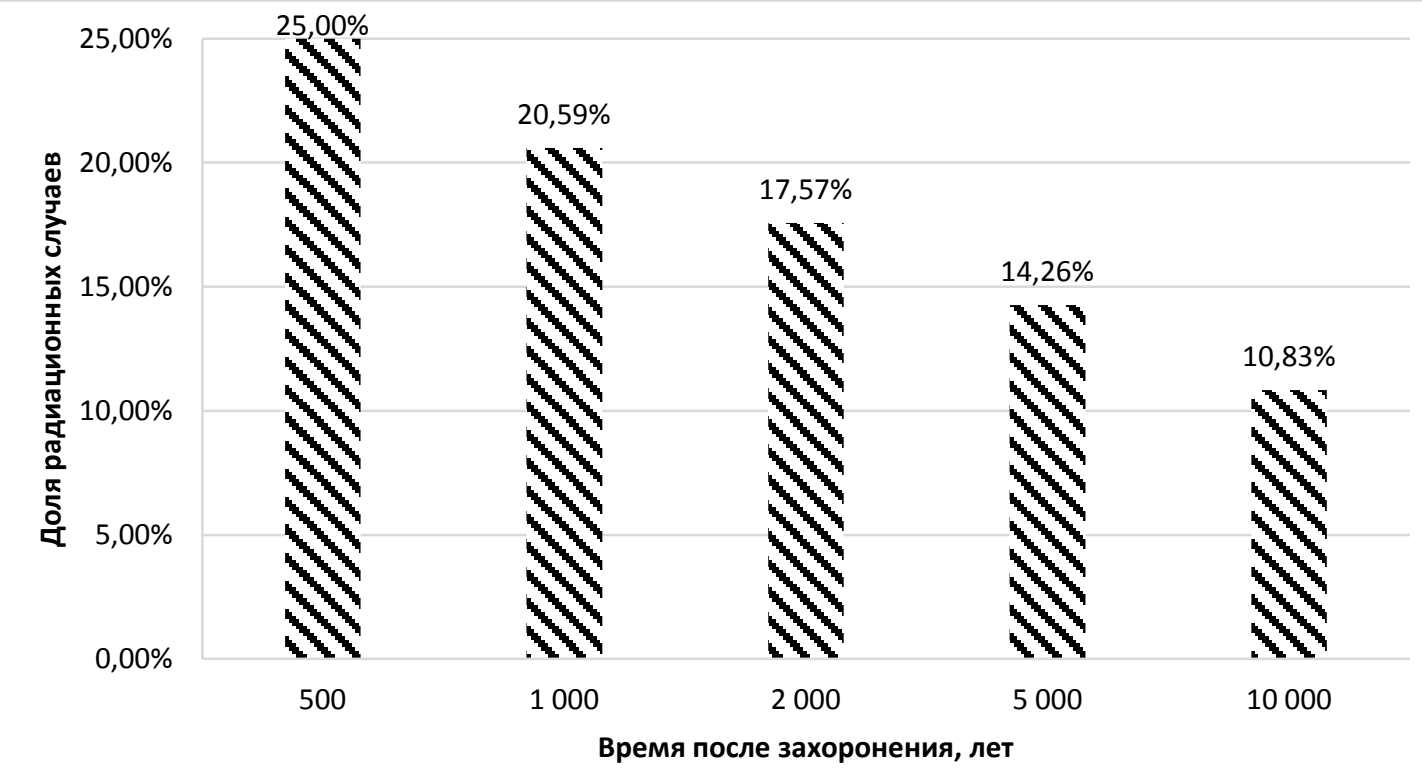

Рис. 20. Доля радиационно-обусловленных случаев в общем числе случаев смерти от $3 \mathrm{HO}$ в год для статической популяции численностью 100000 человек, при проживании в течение всей жизни в районе захоронения отходов ЯЭ, основанной на использовании ТР. 


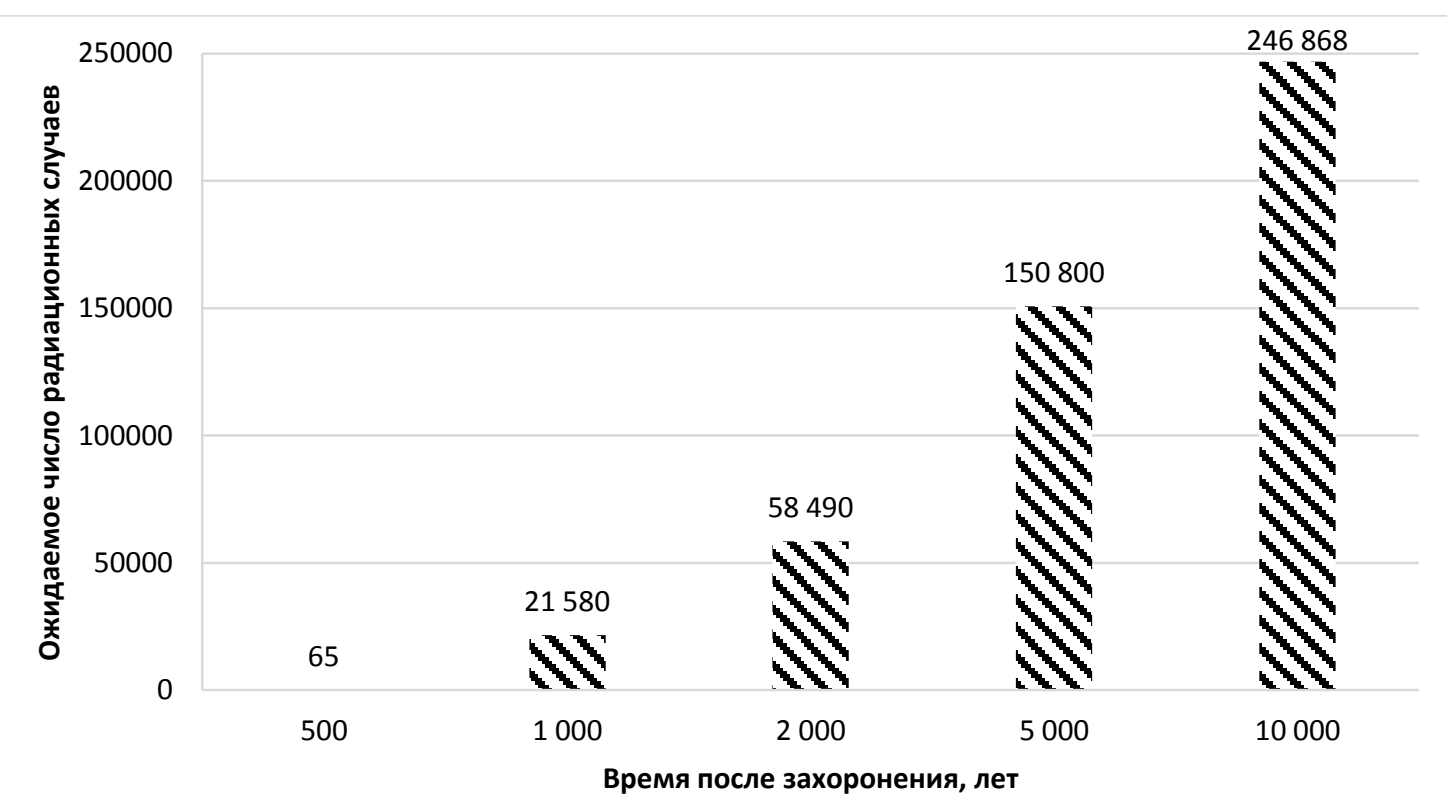

Рис. 21. Накопленное ожидаемое число радиационно-обусловленных случаев смерти от ЗНО в статической популяции численностью 100000 человек, при проживании в течение всей жизни в районе захоронения отходов ЯЭ, основанной на использовании ТР.

\section{Выводы}

1. В модели двухкомпонентной ядерной энергетики (ТР+БР) установлено, что при достижении радиологической эквивалентности РАО и природного уранового сырья (необходимо 100 лет) реализуется эфффект радиологической миграционной эквивалентности на временных интервалах наблюдения (до $10^{9}$ лет).

2. Величина пожизненного атрибутивного риска индукции онкозаболеваний (LAR) для TP в 350 раз больше величины LAR для TP+БР, для достижения радиологической миграционной эквивалентности для TP необходимо более 1 млн лет после захоронения.

3. При потреблении колодезной воды на местах выхода радионуклидов из глубинных захоронений для TP+БР величина LAR не превышает $10^{-5}$ год $^{-1}$. Для TP соответствующее значение LAR составляет $10^{-3}$ год ${ }^{-1}$, значительно превышая современные требования НРБ-99/2009. Основными дозо-риск-образующими радионуклидами при потреблении колодезной воды на временном интервале до 10 тыс. лет после захоронения являются ${ }^{241} \mathrm{Am},{ }^{239} \mathrm{Pu}{ }^{240} \mathrm{Pu}$.

4. Величина радиологического ущерба для ТР превышает аналогичный показатель для ТР+БР на два с половиной порядка и является социально неприемлемой для населения.

5. Исследования по радиологической миграционной эквивалентности необходимо продолжить с учётом основных фракторов неопределённости по коэффициентам распределения $\left(\mathrm{K}_{\mathrm{d}}\right)$ и задержки $\left(\mathrm{k}_{\mathrm{r}}\right)$.

Настоящая работа выполнена в рамках ПН «Прорыв» Госкорпорации «Росатом». 


\section{Литература}

1. Иванов В.К., Чекин С.Ю., Меняйло А.Н., Максютов М.А., Туманов К.А., Кащеева П.В., Ловачёв C.C., Адамов Е.О., Лопаткин А.В. Уровни радиологической защиты населения при реализации принципа радиационной эквивалентности: риск-ориентированный подход //Радиация и риск. 2018. T. 27, № 3. С. 9-23.

2. Атомная энергетика нового поколения: радиологическая состоятельность и экологические преимущества /Под общ. ред. В.К. Иванова, Е.О. Адамова. М.: Изд-во «Перо», 2019. 379 с.

3. Иванов В.К., Чекин С.Ю., Меняйло А.Н., Максютов М.А., Туманов К.А., Кащеева П.В., Ловачёв С.С., Адамов Е.О., Лопаткин А.В. Радиационная и радиологическая эквивалентность РАО при двухкомпонентной ядерной энергетике //Радиация и риск. 2019. Т. 28, № 1. С. 5-25.

4. Радиационная обстановка на территории России и сопредельных государств в 2018 г. Ежегодник. Обнинск: НПО «Тайфун», 2019. 324 с.

5. Крышев И.И., Рязанцев Е.П. Экологическая безопасность ядерно-энергетического комплекса России. М.: ИздАт, 2010. 496 с.

6. Радиоактивность районов АЭС /Под ред. И.И. Крышева. М.: ИАЭ им. И.В. Курчатова, 1991. 126 с.

7. Радиоэкологическая обстановка в регионах расположения предприятий Росатома /Под общей ред. И.И. Линге и И.И. Крышева. М.: «САМ полиграфист», 2015. 296 с.

8. Адамов Е.О., Ганев И.Х. Экологически безупречная ядерная энергетика. М.: НИКИЭТ им. Н.А. Доллежаля, 2007. 145 с.

9. Implications of partitioning and transmutation in radioactive waste management. Technical Reports Series No. 435. IAEA: Vienna, 2004.

10. Адамов Е.О., Ганев И.Х., Лопаткин А.В., Муратов В.Г., Орлов В.В. Трансмутационный топливный цикл в крупномасштабной ядерной энергетике России. М.: ГУП НИКИЭТ, 1999. 252 с.

11. Адамов Е.О., Ганев И.Х., Лопаткин А.В., Муратов В.Г., Орлов В.В. Степень приближения к радиационной эквивалентности высокоактивных отходов и природного урана в топливном цикле ядерной энергетики России //Атомная энергия. 1996. Т. 81, № 6. С. 403-409.

12. Лопаткин А.В., Величкин В.И., Никипелов Б.В., Полуэктов П.П. Радиационная эквивалентность и природоподобие при обращении с радиоактивными отходами //Атомная энергия. 2002. Т. 92, № 4. C. $308-317$.

13. Physics and safety of transmutation systems: a status report. OECD/NEA Report No. 6090. Nuclear Energy Agency, 2006. 120 p.

14. Magill J., Berthou V., Haas D., Galy J., Schenkel R., Wiese H.-W., Heusener G., Tommasi J., Youinou G. Impact limits of partitioning and transmutation scenarios on the radiotoxicity of actinides in radioactive waste //Nucl. Energ. 2003. V. 42, N 5. P. 263-277.

15. Radionuclide retention in geologic media. Workshop Proceedings, Oskarshamn, Sweden, 7-9 May 2001. OECD/NEA Report No. 3061. Nuclear Energy Agency, 2002. 269 p.

16. Waste from innovative types of reactors and fuel cycles. A preliminary study. IAEA Nuclear Energy Series No. NW-T-1.7. Vienna: IAEA, 2019. 117 p.

17. Quantification of radionuclide transfer in terrestrial and freshwater environments for radiological assessments. IAEA TECDOC-1616. Vienna: IAEA, 2009. 624 p.

18. Handbook of parameter values for the prediction of radionuclide transfer in temperate environments. Technical Report Series No. 364. Vienna: IAEA, 1994. 87 p.

19. Handbook of parameter values for the prediction of radionuclide transfer in terrestrial and freshwater environments. Technical Report Series No. 472. Vienna: IAEA, 2010. $194 \mathrm{p}$

20. Bunzl K. Migration of fallout-radionuclides in the soil: effect of non-uniformity of the sorption properties on the activity-depth profiles //Radiat. Environ. Biophys. 2001. V. 40, N 3. P. 237-241. 
21. Routson R.C., Jansen G., Robinson A.V. ${ }^{241} \mathrm{Am},{ }^{237} \mathrm{~Np}$, and ${ }^{99} \mathrm{Tc}$ sorption on two united states subsoils from differing weathering intensity areas //Health Phys. 1977. V. 33, N 4. P. 311-317.

22. Mojida M.A., Vereecken H. On the physical meaning of retardation factor and velocity of a nonlinearly sorbing solute //J. Hydrol. 2005. V. 302. P. 127-136.

23. Милютин В.В., Гелис В.М., Некрасова Н.А., Кононенко О.А., Везенцев А.И., Воловичева Н.А., Королькова С.В. Сорбция радионуклидов Cs, Sr, U и Pu на природных и модифицированных глинах //Радиохимия. 2012. Т. 54, № 1. С. 71-74.

24. McDowell-Boyer L., Kaplan D.I. Distribution coefficients $\left(K_{d} S\right)$, $K_{d}$ distributions, and cellulose degradation product correction factors for the composite analysis. U.S. Department of Energy, 2009

25. Grogan K.P., Fjeld R.A., Kaplan D., DeVol T.A., Coates J.T. Distributions of radionuclide sorption coefficient $\left(K_{d}\right)$ in sub-surface sediments and the implications for transport calculations //J. Environ. Radioact. 2010. V. 101, N 10. P. 847-853.

26. Vandenhove H., Gil-Garcia C., Rigol A., Vidal M. New best estimates for radionuclide solid-liquid distribution coefficients in soils. Part 2: naturally occurring radionuclides //J. Environ. Radioact. 2009. V. 100, N 9. P. 697-703.

27. Gil-Garcia C., Tagami K., Uchida S., Rigol A., Vidal M. New best estimates for radionuclide solid-liquid distribution coefficients in soils. Part 3: miscellany of radionuclides (Cd, Co, Ni, Zn, I, Se, Sb, Pu, Am, and others) //J. Environ. Radioact. 2009. V. 100, N 9. P. 704-715.

28. ICRP, 2012. Compendium of dose coefficients based on ICRP Publication 60. ICRP Publication 119 //Ann. ICRP. 2012. V. 41 (Suppl.). P. 1-130.

29. ICRP, 2007. The 2007 Recommendations of the International Commission on Radiological Protection. ICRP Publication 103 //Ann. ICRP. 2007. V. 37, N 2-4. P. 1-332.

30. Preston D.L., Kusumi S., Tomonaga M., Ron E., Kuramoto A., Kamada N., Dohy H., Matsui T., Nonaka H., Thompson D.E., Soda M., Mabuchi K. Cancer incidence in atomic bomb survivors. Part III. Leukaemia, lymphoma and multiple myeloma, 1950-1987 //Radiat. Res. 1994. V. 137 (Suppl. 2). P. S68-S97.

31. United Nations Scientific Committee on the Effects of Atomic Radiation (UNSCEAR). Effects of ionizing radiation. Vol. 1. UNSCEAR 2006 Report to the General Assembly, Scientific annexes A and B. New York: United Nations, 2008.

32. ICRP Database of Dose Coefficients: Workers and Members of the Public. Ver. 3.0, official website. [Электронный ресурc]. URL: http://www.icrp.org/page.asp?id=145 (дата обращения 16.03.2020)

33. Меняйло А.Н., Чекин С.Ю., Кащеев В.В., Максютов М.А., Корело А.М., Туманов К.А., Пряхин Е.А., Ловачев С.С., Карпенко С.В., Кащеева П.В., Иванов В.К. Пожизненный радиационный риск в результате внешнего и внутреннего облучения: метод оценки //Радиация и риск. 2018. Т. 27, № 1. С. 8-21.

34. Злокачественные новообразования в России в 2017 году (заболеваемость и смертность) /Под ред. А.Д. Каприна, В.В. Старинского, Г.В. Петровой. М.: МНИОИ им. П.А. Герцена - филиал ФГБУ «НМИЦ радиологии» Минздрава России, 2018. 250 с.

35. Иванов В.К., Чекин С.Ю., Меняйло А.Н., Ловачёв С.С., Селёва Н.Г., Бакин Р.И., Ильичев Е.А., Киселёв А.А., Соломатин В.М., Адамов Е.О., Лемехов В.В. Оценка потенциальных радиологических рисков населения при реализации проекта «Прорыв» Госкорпорации «Росатом». Часть 2. Определение радиологического ущерба //Радиация и риск. 2020. Т. 29, № 4. С. 48-67.

36. IAEA Safety Glossary 2018 Edition. Vienna: IAEA, 2019. 263 p.

37. Мишина В. ВВП болен раком //Газета «Коммерсантъ». № 137 от 05.08.2019, с. 5. [Электронный pecypc]. URL: https://www.kommersant.ru/doc/4052457 (дата обращения 14.09.2020). 


\title{
Safety of radioactive waste from two-component nuclear energy system disposed in a deep geological repository for permanent storage: radiological migration equivalence
}

\author{
Ivanov V.K. ${ }^{1,2,3}$, Spirin E.V. ${ }^{3}$, Menyajlo A.N. ${ }^{1,2}$, Chekin S.Yu. ${ }^{1,2}$, Lovachev S.S..$^{1,2}$, \\ Korelo A.M. ${ }^{1,2}$, Tumanov K.A. ${ }^{1,2}$, Solomatin V.M. ${ }^{3}$, Lopatkin A.V. ${ }^{3}$, Adamov E.O. ${ }^{3}$ \\ ${ }^{1}$ A. Tsyb MRRC, Obninsk; \\ ${ }^{2}$ Medinfo LLC, Obninsk; \\ ${ }^{3}$ Joint Stock Company PRORYV, Moscow
}

\begin{abstract}
The article presents analysis of safety of long-lived high level radioactive waste (RW) disposed for permanent storage in a deep geological repository. According to the study protocol it is necessary to estimate the human and environmental health safety of RW, generated in different nuclear fuel cycles, during their long-term stay in the repository. To estimate biological effects, RW composition from thermal reactors in open nuclear fuel cycle ("TR") and from simultaneously operated thermal and fast reactors in closed nuclear cycle ("TR+FR") in different time after their disposal have been evaluated. It is suggested that RW to be safe to humans and the environment if committed effective doses from RW components including minor actinides and fission products and from natural uranium are equivalent (radiation equivalence) or lifetime attributable risks of cancer mortality from RW and natural uranium are equivalent (radiological equivalence). For this purpose it is important to evaluate the time of achievement of radiation or radiological equivalence. To evaluate health effect of RW containing radionuclides on the public and the environment their migration activity has been evaluated with the use of distribution coefficient and retardation factor. Probable annual effective doses to the public from exposure to the radionuclides released from the repository to the biosphere at different time after the RW disposal have been estimated. Radiation doses to the public following the consumption of water from the well installed on the repository, and lifetime attributable risk (LAR) of cancer mortality associated with the exposure to radionuclides contained in "TR " and "TR+FR" generated waste have been evaluated. It turned out that LARs of cancer mortality from "TR+FR" radionuclides is lower than LAR from natural uranium, it means that radiological migration equivalence after its achievement will exists until the repository conditions allow, about 1 billion years. We have found that LARs from "TR+FR" waste is about 100 times lower than the negligible level, $10^{-6}$, established in the Russian National Radiation Safety Standards (NRB-99/2009). Estimated LAR of cancer mortality from "TR"-generated waste is 360 times higher than LAR from "TR+FR"-generated waste. As evaluated for the waste from TR radiological equivalence will be achieved not earlier than 1 million years after permanent disposal. If RW is generated in the closed cycle estimated LAR value from consumption of well water does not exceed $10^{-5}$ year $^{-1}$, if RW is generated in open fuel cycle, the LAR value is $10^{-3}$ year $^{-1}$, this is socially unacceptable risk. In the first 10 thousand years after the disposal the major dose-and risk-forming radionuclides in the well water will be ${ }^{241} \mathrm{Am},{ }^{239} \mathrm{Pu} n{ }^{240} \mathrm{Pu}$. Estimates of radiation detriment from "TR" generated waste put to the permanent deep geological disposal are given in the article.
\end{abstract}

Key words: radiological equivalence, radiological migration equivalence, committed effective doses, thermal reactors, fast reactors, lifetime attributable risk, radiation detriment.

\section{References}

1. Ivanov V.K., Chekin S.Yu., Menyajlo A.N., Maksioutov M.A., Tumanov K.A., Kashcheeva P.V., Lovachev S.S., Adamov E.O., Lopatkin A.V. Application of the radiation equivalence principle to estimation of levels of radiological protection of the population: risk-oriented approach. Radiatsiya $i$ risk - Radiation and Risk, 2018, vol. 27, no. 3, pp. 9-23. (In Russian).

2. New generation nuclear power: radiological viability and environmental benefits. Eds.: V.K. Ivanov, E.O. Adamov. Mocsow, Pero, 2019. 379 p. (In Russian).

Ivanov V.K. - Deputy Director of A. Tsyb MRRC, Chief Radioecologist of Project PRORYV, Chairman of RSCRP, Corresponding Member of RAS, D. Sc., Tech.; Menyajlo A.N. - Senior Researcher, C. Sc., Biol.; Chekin S.Yu.* - Head of Lab.; Lovachev S.S. - Research Assistant; Korelo A.M. - Senior Researcher; Tumanov K.A. - Head of Lab., C. Sc., Biol. A. Tsyb MRRC, Medinfo. Spirin E.V. - Chief Researcher of the Dep. of the Chief Radioecologist, Project PRORYV, D. Sc., Biol.; Solomatin V.M. - Head of Dep. of the Chief Radioecologist, Project PRORYV, C. Sc., Biol.; Lopatkin A.V. - Research Advisor for RE, D. Sc., Tech.; Adamov E.O. - Research Advisor, Project PRORYV, D. Sc., Tech., Prof. JSC PRORYV.

*Contacts: 4 Korolyov str., Obninsk, Kaluga region, Russia, 249035. Tel.: (484) 399-30-79; e-mail: nrer@obninsk.com. 
3. Ivanov V.K., Chekin S.Yu., Menyajlo A.N., Maksioutov M.A., Tumanov K.A., Kashcheeva P.V., Lovachev S.S., Adamov E.O., Lopatkin A.V. Radiation and radiological equalities between natural uranium and radioactive waste in innovative two-component nuclear energy system. Radiatsiya $i$ risk - Radiation and Risk, 2019, vol. 28, no. 1, pp. 5-25. (In Russian).

4. Radiation situation within the territory of Russia and neighboring states in 2018. Annual. Obninsk, RPA "Typhoon”, 2019. 324 p. (In Russian).

5. Kryshev I.I., Ryazantsev E.P. Environmental safety of the nuclear power engineering complex of Russia. Moscow, IzdAT, 2010. 496 p. (In Russian).

6. Radioactivity of NPP region. Ed.: I.I. Kryshev. Moscow, I.V. Kurchatov's IAE, 1991. 126 p. (In Russian).

7. Radioecological situation in the regions of Rosatom enterprises. Eds.: I.I. Linge, I.I. Kryshev. Moscow, SAM poligrafist, 2015. 296 p. (In Russian).

8. Adamov E.O., Ganev I.Kh. Environmentally pure nuclear power. Moscow, N. Dollezhal PERDI, 2007. 145 p. (In Russian).

9. Implications of partitioning and transmutation in radioactive waste management. Technical Reports Series No. 435. IAEA, Vienna, 2004.

10. Adamov E.O., Ganev I.Kh., Lopatkin A.V., Muratov V.G., Orlov V.V. Transmutation fuel cycle in Russia's large-scale nuclear energy system. Moscow, GUP NIKIET, 1999. 252 p. (In Russian).

11. Adamov E.O., Ganev I.Kh., Lopatkin A.V., Muratov V.G., Orlov V.V. Approximations to radiation equivalence between high-level wastes and natural uranium in the fuel cycle of Russian nuclear power. Atomnaya energiya - Atomic Energy, 1996, vol. 81, no. 6, pp. 403-409. (In Russian).

12. Lopatkin A.V., Velichkin V.I., Nikipelov B.V., Poluektov P.P. Radiation equivalence and natural similitude in handling radioactive wastes. Atomnaya energiya - Atomic Energy, 2002, vol. 92, no. 4, pp. 308-317. (In Russian).

13. Physics and safety of transmutation systems: a status report. OECD/NEA Report No. 6090. Nuclear Energy Agency, 2006. $120 \mathrm{p}$

14. Magill J., Berthou V., Haas D., Galy J., Schenkel R., Wiese H.-W., Heusener G., Tommasi J., Youinou G. Impact limits of partitioning and transmutation scenarios on the radiotoxicity of actinides in radioactive waste. Nucl. Energ., 2003, vol. 42, no. 5, pp. 263-277.

15. Radionuclide retention in geologic media. Workshop Proceedings, Oskarshamn, Sweden, 7-9 May 2001. OECD/NEA Report No. 3061. Nuclear Energy Agency, 2002. 269 p.

16. Waste from innovative types of reactors and fuel cycles. A preliminary study. IAEA Nuclear Energy Series No. NW-T-1.7. Vienna, IAEA, 2019.117 p.

17. Quantification of radionuclide transfer in terrestrial and freshwater environments for radiological assessments. IAEA TECDOC-1616. Vienna, IAEA, 2009. 624 p.

18. Handbook of parameter values for the prediction of radionuclide transfer in temperate environments. Technical Report Series No. 364. Vienna, IAEA, 1994. 87 p.

19. Handbook of parameter values for the prediction of radionuclide transfer in terrestrial and freshwater environments. Technical Report Series No. 472. Vienna, IAEA, 2010. 194 p.

20. Bunzl K. Migration of fallout-radionuclides in the soil: effect of non-uniformity of the sorption properties on the activity-depth profiles. Radiat. Environ. Biophys., 2001, vol. 40, no. 3, pp. 237-241.

21. Routson R.C., Jansen G., Robinson A.V. ${ }^{241} \mathrm{Am},{ }^{237} \mathrm{~Np}$, and ${ }^{99} \mathrm{Tc}$ sorption on two united states subsoils from differing weathering intensity areas. Health Phys., 1977, vol. 33, no. 4, pp. 311-317.

22. Mojida M.A., Vereecken H. On the physical meaning of retardation factor and velocity of a nonlinearly sorbing solute. J. Hydrol., 2005, vol. 302, pp. 127-136. 
23. Mulyutin V.V., Gelis V.M., Nekrasova N.A., Kononenko O.A., Vezentsev A.I., Volovicheva N.A., Korol'kova S.V. Sorption of $\mathrm{Cs}, \mathrm{Sr}, \mathrm{U}$ and $\mathrm{Pu}$ radionuclides on natural and modified clays. Radiokhimiya Radiochemistry, 2012, vol. 54, no. 1, pp. 71-74. (In Russian).

24. McDowell-Boyer L., Kaplan D.I. Distribution coefficients $\left(K_{d} S\right), K_{d}$ distributions, and cellulose degradation product correction factors for the composite analysis. U.S. Department of Energy, 2009.

25. Grogan K.P., Fjeld R.A., Kaplan D., DeVol T.A., Coates J.T. Distributions of radionuclide sorption coefficient $\left(\mathrm{K}_{\mathrm{d}}\right)$ in sub-surface sediments and the implications for transport calculations. J. Environ. Radioact., 2010, vol. 101, no. 10, pp. 847-853.

26. Vandenhove H., Gil-Garcia C., Rigol A., Vidal M. New best estimates for radionuclide solid-liquid distribution coefficients in soils. Part 2: naturally occurring radionuclides. J. Environ. Radioact., 2009, vol. 100, no. 9, pp. 697-703.

27. Gil-Garcia C., Tagami K., Uchida S., Rigol A., Vidal M. New best estimates for radionuclide solid-liquid distribution coefficients in soils. Part 3: miscellany of radionuclides (Cd, Co, Ni, Zn, I, Se, Sb, Pu, Am, and others). J. Environ. Radioact., 2009, vol. 100, no. 9, pp. 704-715.

28. ICRP, 2012. Compendium of dose coefficients based on ICRP Publication 60. ICRP Publication 119. Ann. ICRP, 2012, vol. 41 (Suppl.), pp. 1-130.

29. ICRP, 2007. The 2007 Recommendations of the International Commission on Radiological Protection. ICRP Publication 103. Ann. ICRP, 2007, vol. 37, no. 2-4, pp. 1-332.

30. Preston D.L., Kusumi S., Tomonaga M., Ron E., Kuramoto A., Kamada N., Dohy H., Matsui T., Nonaka H., Thompson D.E., Soda M., Mabuchi K. Cancer incidence in atomic bomb survivors. Part III. Leukaemia, lymphoma and multiple myeloma, 1950-1987. Radiat. Res.,1994, vol. 137 (Suppl. 2), pp. S68-S97.

31. United Nations Scientific Committee on the Effects of Atomic Radiation (UNSCEAR). Effects of ionizing radiation. Vol. 1. UNSCEAR 2006 Report to the General Assembly, Scientific annexes A and B. New York, United Nations, 2008.

32. ICRP Database of Dose Coefficients: Workers and Members of the Public; Ver. 3.0, official website. Available at: http://www.icrp.org/page.asp?id=402 (Accessed 16.03.2020).

33. Menyajlo A.N., Chekin S.Yu., Kashcheev V.V., Maksioutov M.A., Korelo A.M., Tumanov K.A., Pryakhin E.A., Lovachev S.S., Karpenko S.V., Kashcheeva P.V., Ivanov V.K. Lifetime attributable risks from external and internal exposure to radiation: method for estimating. Radiatsiya i risk - Radiation and Risk, 2018, vol. 27, no. 1, pp. 8-21. (In Russian).

34. Malignant neoplasms in Russia in 2017 (morbidity and mortality). Eds.: A.D. Kaprin, V.V. Starinskiy, G.V. Petrova. Moscow, P. Hertsen MORI, 2018. 250 p. (In Russian).

35. Ivanov V.K., Chekin S.Yu., Menyajlo A.N., Lovachev S.S., Seleva N.G., Bakin R.I., Ilichev E.A., Kiselev A.A., Solomatin V.M., Adamov E.O., Lemekhov V.V., Proukhin A.V. Potential radiation risks to the population during implementation of the Rosatom project "Proryv". Part 2. Evaluation of radiation detriment. Radiatsiya i risk - Radiation and Risk, 2020, vol. 29, no. 4, pp. 48-67. (In Russian).

36. IAEA Safety Glossary 2018 Edition. Vienna, IAEA, 2019. 263 p.

37. Mishina V. GDP is sick with cancer. Gazeta "Kommersant» - Newspaper "Kommersant", 2019, p. 5. Available at: https://www.kommersant.ru/doc/4052457 (Accessed 14.09.2020). 